\title{
Behaviour of eccentrically inclined loaded rectangular foundation on reinforced sand
}

https://doi.org/10.2478/sgem-2021-0003

received July 27, 2020; accepted February 6, 2021.

\begin{abstract}
This study presents the behaviour of model footing resting over unreinforced and reinforced sand bed under different loading conditions carried out experimentally. The parameters investigated in this study includes the number of reinforced layers $(N=0,1,2,3$, 4), embedment ratio $\left(D_{f} / B=0,0.5,1.0\right)$, eccentric and inclined ratio $(e / L, e / B=0,0.05,0.10,0.15)$ and $\left(a=0^{\circ}\right.$, $\left.7^{\circ}, 14^{\circ}\right)$. The test sand was reinforced with bi-axial geogrid (Bx20/20). The test results show that the ultimate bearing capacities decrease with axial eccentricity and inclination of applied loads. The test results also show that the depth of model footing increase zero to $B$ ( $B$ = width of model footing), an increase of ultimate bearing capacity (UBC) approximated at $93 \%$. Similarly, the multi-layered geogrid reinforced sand ( $N=0$ to 4 ) increases the UBC by about $75 \%$. The bearing capacity ratio $(B C R)$ of the model footing increases with an increasing load eccentricity to the core boundary of footing; if the load eccentricities increase continuity, the $B C R$ decreases. The tilt of the model footing is increased by increasing the eccentricity and decreases with increasing the number of reinforcing layers.
\end{abstract}

Keywords: Eccentric loading; load inclination; ultimate bearing capacity (UBC); rectangular footing; geogrid.

\section{Introduction}

The concept of ultimate bearing capacity (UBC) of shallow foundations under varied loads is important for foundation engineers. In the design of foundations, the soil classification, behaviour and UBC are the most essential factors. There are two criteria to select the UBC

\footnotetext{
*Corresponding author: Sujata Gupta, Department of Civil Engineering, National Institute of Technology Kurukshetra, India-136119, E-mail: sujalbansal1990@gmail.com

Anupam Mital, Department of Civil Engineering, National Institute of Technology Kurukshetra, India-136119
}

for shallow foundations, namely the stability against shear failure and the settlement within the safe limit.

A foundation under load will undergo settlement due to the horizontal and vertical movement of soil particles below the foundation. In the case of centric vertical load on the footing, stress distribution will be uniform below the footing and the footing will undergo equal settlement at both edges. On the other hand, if the load is eccentric, the stress distribution below the footing will be nonuniform causing unequal settlement at two edges which will result in the tilt of footing. The tilt will increase with the increasing eccentricity to width ratio $(e / B)$. When the eccentricity to width ratio $(e / B)$ is greater than $1 / 6$, the edge of the footing away from the load will lose it in contact with the soil, which will result in the reduction of effective width of footing and hence reduction of UBC of the foundation. Nowadays the use of geogrid has increased due to its high tensile strength at low strain, open grid structure that causes bonding between geogrid and foundation soil, long service life, lightweight. High modulus polymer materials such as polypropylene and polyethylene are used to manufacture the geogrid. Geogrid may be of two types, i.e. biaxial and uniaxial geogrid, depending on the nature of manufacturing.

In soil engineering practice, several techniques for soil improvement have been used to modify the soil behaviour and reduce the foundation settlement. In the past few years, it was found that the value of UBC increases with the use of reinforcing materials such as geotextile, geosynthetics and geogrid. Many types of research have been done on the behaviour of UBC of shallow foundation supported by unreinforced and reinforced sand using a laboratory model (Meyerhof [15], Das et al. [5], Yoo [31], Shin et al. [27, 28], Michalowski [16], Patra et al. [21, 22], El Sawwaf [25], Sitharam and Sireesh [29], Ornek [19]). From these studies, it can be concluded that the reinforced soil improves the UBC and reduces the foundation settlement. Recently, the effects of load eccentricity, inclination and combined effects of both eccentric and inclined loads on the UBC of shallow foundation located over reinforced and unreinforced sand bed have been studied experimentally, analytically 
1. Loading frame

2. Screw jack

3. Proving ring

4. Dial gauge

5. Model footing

6. Model sand

7. Test tank

8. Bx20/20 Bi-axial geogrid reinforcement layers

$B=$ width of model footing

$D / B=$ Depth of embedment

$b_{r}=$ Width of geogrid layers

$N=$ Number of geogrid layers

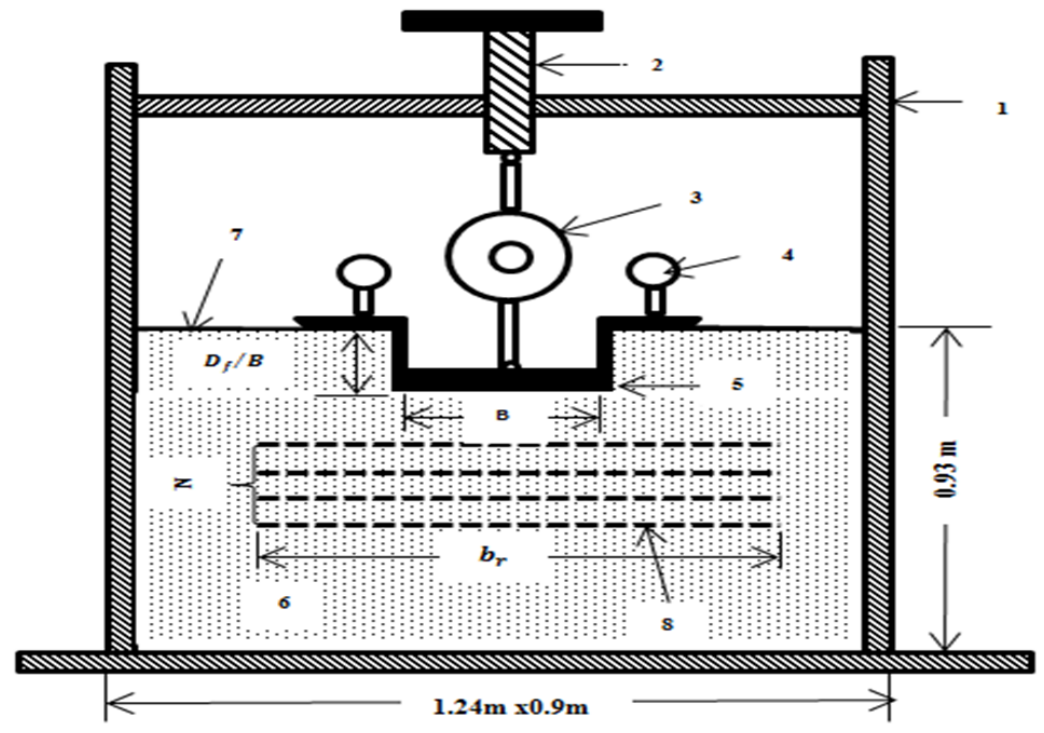

Figure 1(a): Schematic view of the test setup.

and numerically by different investigators (Hjiaj [9], Kumar et al. [11,12], Foye et al. [6], Padmini et al. [20], Loukidis et al. [14], Latha and Somwanshi [13], Nazir and Azzam [17], Sawwaf and Nazir [26], Patra et al. [23], Rabi Narayan Behera [3], Krabbenhoft, et al. [10], Ornek [19], Badakhshan and Noorzad [1, 2], Ganesh et al. [7]). All researchers concluded that the value of UBC rises with increasing the number of geogrid reinforcing layers because the soil-reinforcement contains a series of interlocking cells that can keep the soil within its pockets and making an interlocking action between soil and geogrid. The interlocking action permits the geogrid to bear the horizontal stresses beneath the foundation and transfer them to the adjacent stable layer of the soil, which improves the vertical behaviour of the model foundation.

Several researchers studied the effect on strip footing subjected to centrically inclined loads. Little work is reported in the literature on the problem of strip footings subjected to eccentric-inclined loads. It is seen that to date no study is performed to address the effects of eccentrically inclined loads in both dimensions, i.e. lateral and longitudinal. The purpose of the study is to investigate the behaviour of model rectangular footing placed over multiple layers of the geogrid reinforced sand subjected to eccentric-inclined loads in both dimensions. The non-dimensional parameters called bearing capacity ratio $(B C R)$ and settlement ratio $(S R)$ are also introduced in this study. The test results demonstrate the potential benefit of using soil reinforcement with embedment depth under eccentric and inclined loads. The study concluded that the UBC increases with the increasing number of

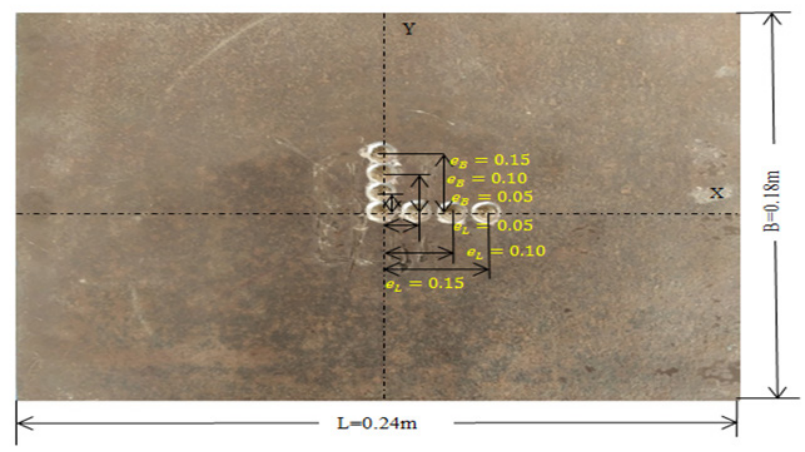

Figure 1(b): Top view of model footing with eccentric holes in both dimensions.

reinforcing layers or increasing in the area of footing or both. Furthermore, the optimum layer of reinforcement was found that $N=3$ because the UBC increases at the third layer of reinforcement and after that, the rate of load increment becomes much less.

\section{Laboratory model test}

\subsection{Model box}

Fig. 1 shows the schematic view of the experimental model apparatus used in this study. The test tank is rectangular, having dimensions of $1.24 \mathrm{~m} \times 0.90 \mathrm{~m} \times 0.93 \mathrm{~m}\left(\mathrm{~L}^{\prime} \mathrm{B}^{\prime} \mathrm{H}\right)$. All sides of the test tank were braced using horizontal steel beams. The horizontal steel beams were fitted at mid- 


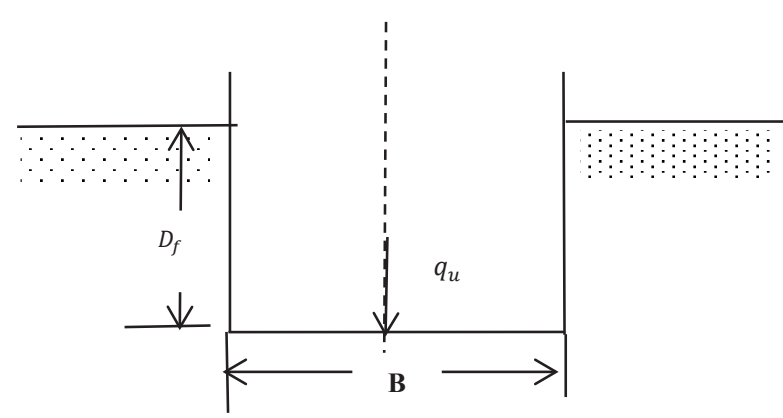

(a)

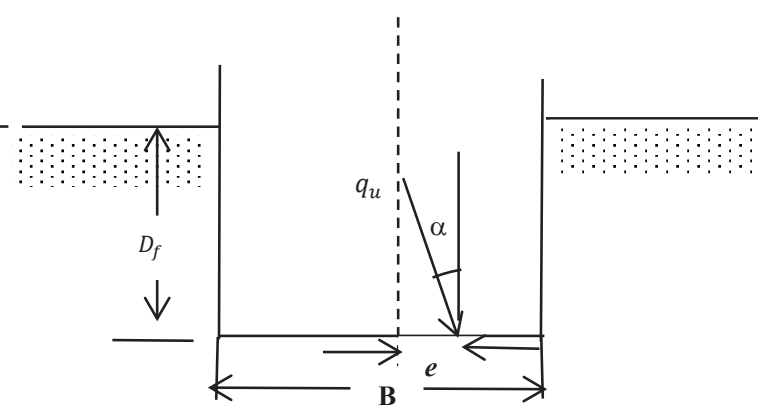

(b)

Figure 1(c): Ultimate load per unit length $q_{u} q_{u}$ on a model footing: (a) axial centric load; (b) eccentric-inclined load.

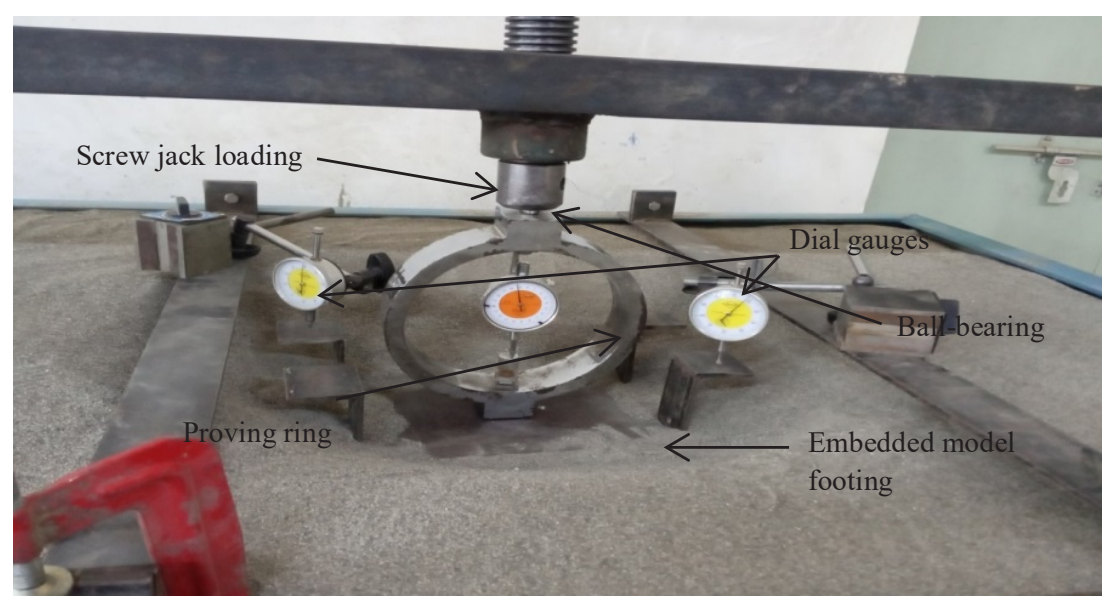

Figure 2(a): Test arrangements of embedded model footing.

depth of the test tank to avoid bulging during the model plate load test.

\subsection{Model footing}

Rectangular shape model footing was made from a mild steel plate, having dimensions of $0.24 \mathrm{~m} \times 0.18 \mathrm{~m} \times 0.015$ $\mathrm{m}\left(\mathrm{L}^{\prime} \mathrm{B}^{\prime} \mathrm{T}\right)$. Holes were made at the desired centric and eccentric points to accommodate the ball-bearing as shown in Fig. 1(b). The holes represented the eccentric points $e_{L}$ and $e_{B}$ in both dimensions, i.e. lateral and longitudinal. Fig. 1(c) shows the ultimate load-bearing capacity of model footing subjected to axial centric and eccentric-inclined load.

\subsection{Loading arrangements}

In this study, manually operated screw jack loading was used. The ultimate load was calculated with the help of a pre-calibrated proving ring. The displacement of footing was noted with the help of two dial gauges having the least count $0.01 \mathrm{~mm}$ arranged on the footing diagonally. The load was transferred to the model footing with the help of ball-bearing. Fig. 2(a) shows the test arrangements of embedded model footing. During testing, three fixed frames were used for axial vertical and inclined loading $\left(\alpha=0^{\circ}, 7^{\circ}\right.$ and $\left.14^{\circ}\right)$ as shown in Fig. 2(b).

\subsection{Test material}

\subsubsection{Sand}

The sand was collected locally from the riverbed of Yamuna River, Yamuna Nagar (India). It was free from roots and organic matters, etc. Physical properties and gradation curves of subjected soil have been tabulated and shown in Table 1 and Fig. 3, respectively. 


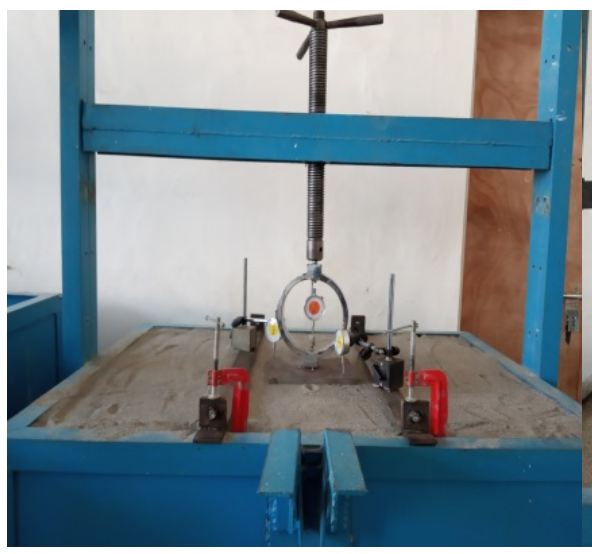

(a)

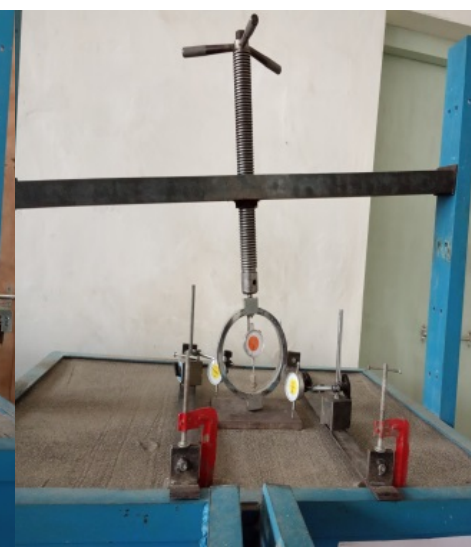

(b)

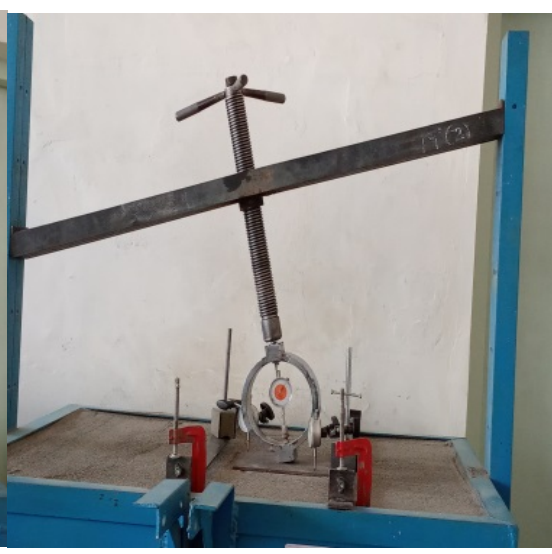

(c)

Figure 2(b): Experimental test setup: (a) horizontal frame; (b) $7^{\circ}$ inclined frame; (c) $14^{\circ}$ inclined frame.

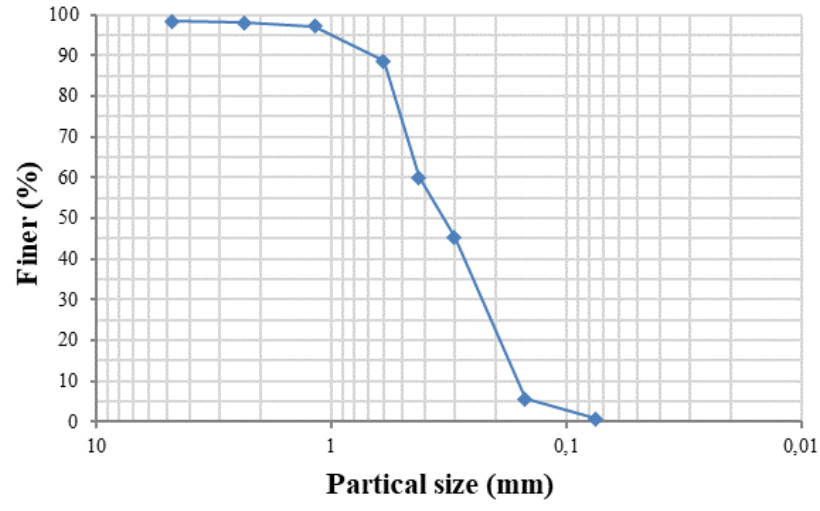

Figure 3: Grain size distribution curve.

\subsubsection{Geogrid}

In this study, polypropylene (PP) bi-axial geogrid (Bx20/20) having an ultimate tensile strength of about $7 \mathrm{kN} / \mathrm{m}^{2}$ was used for reinforcing the sand. The geogrid was provided by Maruti Rubplast Private Limited. The geogrid had a square-shaped aperture $\left(0.039 \mathrm{~m}^{\prime} 0.039 \mathrm{~m}\right)$ and provides an equal ultimate tensile strength in all directions.

\section{Testing program and methodology}

\subsection{Placement of sand}

The sand was placed in the test tank in a layer of $0.02 \mathrm{~m}$ from a fixed height of $0.20 \mathrm{~m}$ by rainfall method. To achieve the desired relative density, it was determined a priori by
Table 1: Properties of Yamuna sand.

\begin{tabular}{ll}
\hline Sand Properties & Value \\
\hline Soil type & $\mathrm{SP}$ \\
Specific gravity, $G$ & 2.65 \\
Effective particle size, $D_{10}(\mathrm{~mm})$ & 0.17 \\
Uniformity coefficient, $C_{u}$ & 3.53 \\
Coefficient of curvature, $C_{c}$ & 0.80 \\
Working dry density, $\gamma_{d}\left(\mathrm{kN} / \mathrm{m}^{3}\right)$ & 15.71 \\
Maximum dry unit weight, $\gamma_{d(\max )}\left(\mathrm{kN} / \mathrm{m}^{3}\right)$ & 17.5 \\
Minimum dry unit weight, $\gamma_{d(\min )}\left(\mathrm{kN} / \mathrm{m}^{3}\right)$ & 12.9 \\
Angle of internal friction, $\left(\phi^{\circ}\right)$ & 36 \\
Maximum void ratio, $e_{\max }$ & 0.77 \\
Minimum void ratio, $e_{\min }$ & 0.50 \\
\hline
\end{tabular}

performing a series of trials with different heights of fall. In each trial, the densities were monitored by collecting samples in a small container of known volume placed at a different location in the test tank. In all model tests, the average unit weight and relative density of the sand were kept as $15.71 \mathrm{kN} / \mathrm{m}^{3}$ and $68 \%$, respectively. While doing the experiment the tank was fully emptied before filling sand for the next experiment. So, the case of the densification of sand at the bottom layers can be discarded.

\subsection{Placement of geogrid}

The factors that affect the behaviour of shallow foundation resting on reinforced sand are $u_{r} / B, h_{r} / B$ and $b_{r} / B$. After the 


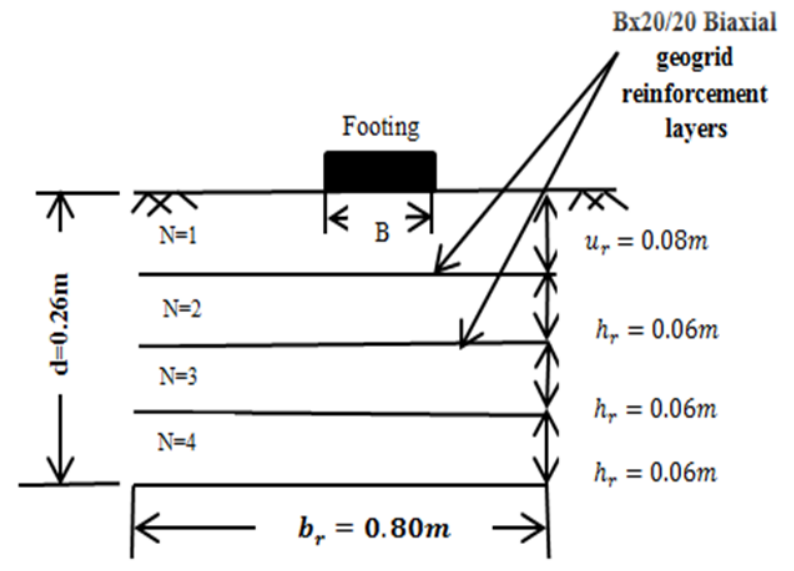

Figure 4(a): Cross-section of adopted criteria for placement of geogrid.

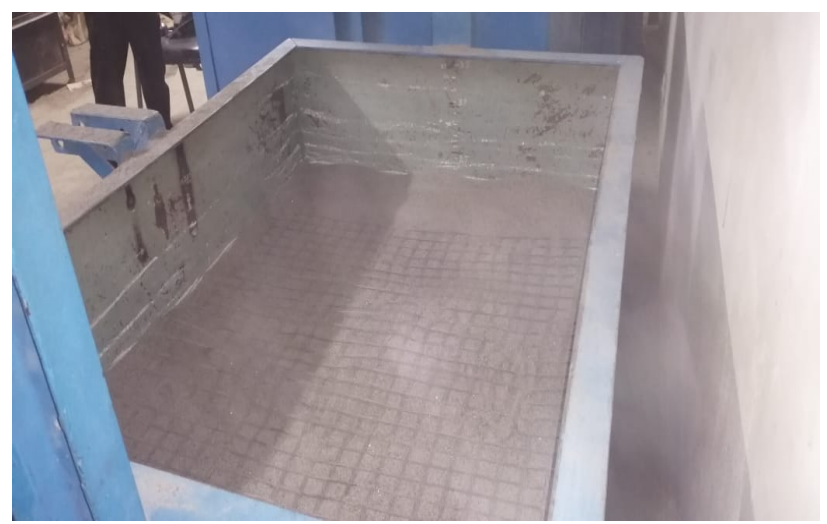

Figure 4(b): Photographic image of placed geogrid.

brief study, it has been established that the values of $\left(u_{r} / B\right)$ and $\left(h_{r} / B\right)$ range from 0.25 to 0.5 (Guido et al. [8]) and 0.25 to 0.4 (Shin and Das [27]), respectively. Omar et al. [18] reported that $\left(b_{r} / B\right)$ should be kept as 8 for strip footing and 4.5 for square footing. During testing width of geogrid was kept as $0.80 \mathrm{~m}$. The first layer of geogrid was placed at $0.08 \mathrm{~m}$ beneath the model foundation and afterward, other layers of geogrid were placed at $0.06 \mathrm{~m}$ distance apart from each other vertically as shown in Fig. 4(a). The reinforced depth beneath the footing can be expressed in terms of Eq. (1).

$$
d=u_{r}+(N-1) h_{r}
$$

where $u_{r}$ is the depth of first reinforced layer beneath the model foundation, $h_{r}$ is the distance between consecutive layers of geogrid and $N$ is the number of geogrid reinforced layers. The placement of geogrid is shown in Fig. 4(b).

\subsection{Testing parameters}

Three-hundred and fifteen numbers of experiments were conducted in total to examine the effects of model footing with varied parameters including the number of the geogrid reinforced layers $(N)$, embedment ratio $\left(D_{f} / B\right)$ and eccentricity ratio $(e / B, e / L)$ with a load of inclination $(a)$.

\section{Result and discussion}

A series of model tests were conducted using rectangular footing with embedment ratio $\left(D_{f} / B=0,0.5,1.0\right)$ on unreinforced and reinforced sand bed subjected to eccentric and inclined loads in both dimensions. Settlement corresponding to each load increment was noted with the help of two sensitive dial gauges having least count of $0.01 \mathrm{~mm}$ arranged on the footing diagonally. The tests were continued until the applied load was reduced. At the end of each test, the sand was excavated to maintain the relative density for the next experiment. The load-settlement curves have been plotted at the end of the experimental analysis process. UBC for each test was determined from the load-settlement curve by using the double-tangent method [30]. Furthermore, BCRand SR are used to express and compare the test data from different loading conditions.

\subsection{Model test results}

Various tests were performed to examine the behaviour of model footing with variable parameters such as depth of embedment $\left(D_{f} / B\right)$, eccentricity $(e / L, e / B)$ and a load of inclination $(\alpha)$. The effects of eccentric and inclined load on model footing were studied through the model plate load tests. Some tests were repeated twice to check the obtained test data. Settlement corresponding to each load increment has been noted and the load-settlement curve has been plotted. The UBC has been found from the load-settlement curve by using the double-tangent method and shown in $\left(D_{f} / B=1\right)$ in Fig. 5. In this method, two tangent lines have been plotted, one at the start of the load-settlement curve and the second at the end of the load-settlement curve, then the intersection point of two tangent lines considered as UBC [4]. Fig. 5 shows the variation of the load-settlement curve with embedded depth $\left(D_{f} / B, 0,0.5,1.0\right)$ of model footing at axial centric load. From the graph, it can be seen that the UBC increases 


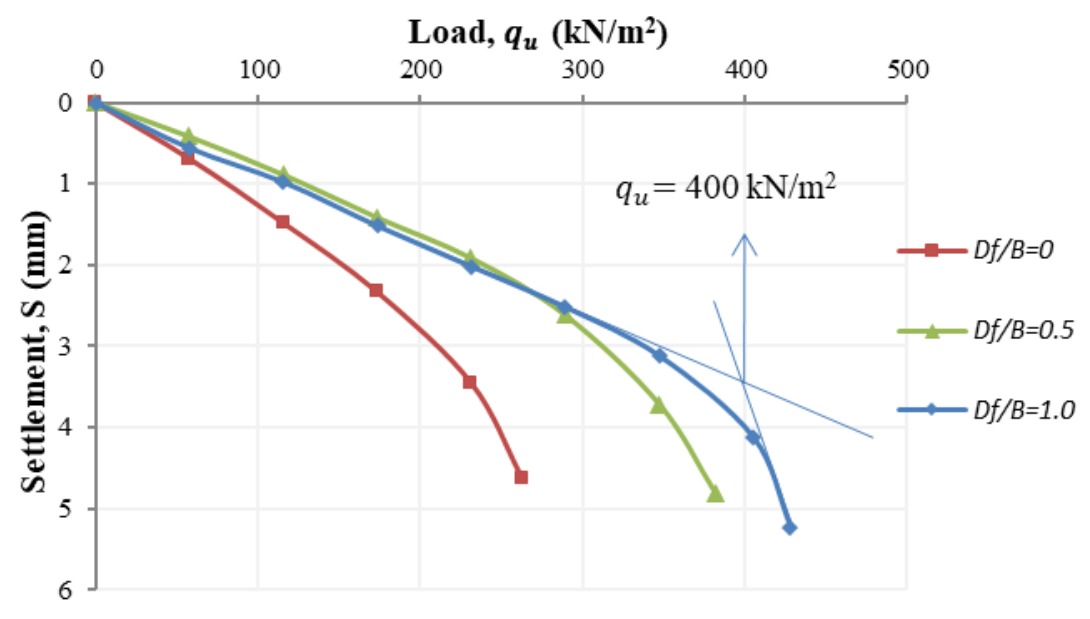

Figure 5: Variation of $\mathrm{L}-\mathrm{S}$ curve for $D_{f} / B$ at axial centric loading $\left(e=0, \mathrm{a}=0^{\circ}\right)$.

with the depth of embedment and the settlement is also increased with the same.

\subsection{Analysis of the test results}

In the present study, a non-dimensional parameter called bearing capacity ratio $(B C R)$ is used to calculate the effects of improvement utilising reinforcement layers on increasing the UBC. It is defined as the ratio of UBC of reinforced soil to the UBC of unreinforced soil (Eq. (2)). To analyse the footing settlement, $S R$ is proposed and defined as the ratio of footing settlement in reinforced soil to the unreinforced soil condition (Eq. (3)).

$$
\begin{aligned}
B C R & =\frac{q_{u(\text { reinforced })}}{q_{u(\text { unreinforced })}} \\
S R & =\frac{S_{u(\text { reinforced })}}{S_{u(\text { unreinforced })}}
\end{aligned}
$$

where $q_{u}$ is the ultimate bearing capacity and $S_{u}$ is the footing settlement at the ultimate bearing capacity. The factor $q_{u(e-i)} / q_{u(e-i=0)}$ is also calculated for both unreinforced sand reinforced sand conditions, which are presented in Tables 2 to 5 , where $q_{u(e-i)}$ is the ultimate bearing capacity of eccentrically inclined load and $q_{u(e-i=0)}$ is the ultimate bearing capacity of centrically applied loads.

\subsubsection{Effect of load eccentricity}

In the case of eccentric loading, the UBC value is calculated from the load-settlement curves that are shown in Fig. 6(a). From the graphs, it can be concluded that the embedment depth ratio $D_{f} / B$ has a significant effect on the reduction of the load eccentricity, where increasing the depth ratio reduced the effect of the eccentricity ratio. The $B C R$ and $S R$ were calculated using Eqs (2) and (3), and the results are presented in Tables 2 and 3 for both dimensions. It can be inferred from both tables that as the load eccentricity increases $B C R$ increases significantly. The results also show that the $B C R$ significantly increased with the increase in the number of reinforcing layers. Also, it is noticed that there is an optimum value of $(N)$ after which a little increase in the value of $B C R$ is observed. This increase in $B C R$ for eccentrically loaded footing, in comparison with centrically loaded footing, is previously shown in an experiment by Sadoglu et al. [24] for strip footing on geotextile reinforced sand. A similar conclusion is also reported by Sawwaf and Nazir [26] for eccentrically loaded ring footing on reinforced layered soil. It is observed that by increasing the number of the reinforcement layers from one layer to three layers the $B C R$ increases.

\subsubsection{Effect of load inclination}

The load-settlement curve for inclined loading with an embedment depth is shown in Fig. 6(b). The centric loads were applied with different inclination angles changed from $0^{\circ}$ to $14^{\circ}$. The ultimate load decreases as the load inclination angle increases and it is expected that $q_{u}$ reaches its maximum value at vertical loading (i.e. $\mathrm{a}=$ $0^{\circ}$ ). The results of $B C R$ and $S R$ are presented in Table 4 . According to the theoretical solutions, the $B C R$ increases with an increase in inclination angle at any embedment depth $D_{f} / B$. 
Load, $q_{u}\left(\mathrm{kN} / \mathrm{m}^{2}\right)$

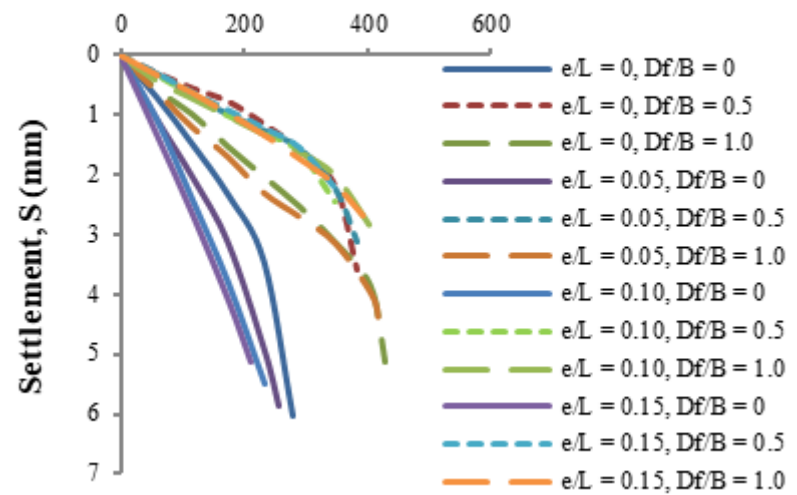

(a)

\section{Load, $q_{u}\left(\mathrm{kN} / \mathrm{m}^{2}\right)$}

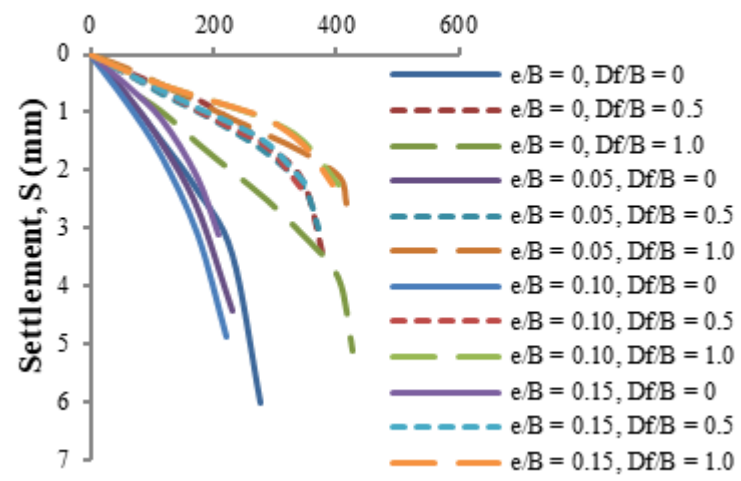

(b)

Figure 6: (a) Variation of L-S curve for eccentric loading with an embedment depth $D_{f} / B$ along with (a) larger dimension $(e / L)$ and (b) smaller dimension $(e / B)$

Table 2: Results of eccentrically loaded $(e / L)$ rectangular footing in unreinforced and reinforced sand conditions.

\begin{tabular}{|c|c|c|c|c|c|c|c|}
\hline$\overline{D_{f} / \mathrm{B}}$ & $\alpha^{\circ}$ & $N$ & $\boldsymbol{q}_{u}$ & $\boldsymbol{S}_{u}$ & $B C R$ & $S R$ & $\frac{q_{u(e-i)}}{q_{u(e-i=0)}}$ \\
\hline 0 & 0 & 0 & 212 & 2.2 & 1.00 & 1.00 & 1.00 \\
\hline 0 & 1 & 0 & 240 & 3.8 & 1.13 & 1.73 & 1.00 \\
\hline 0 & 2 & 0 & 282 & 4.1 & 1.33 & 1.86 & 1.00 \\
\hline 0 & 3 & 0 & 348 & 4.7 & 1.64 & 2.14 & 1.00 \\
\hline 0 & 4 & 0 & 368 & 6 & 1.74 & 2.73 & 1.00 \\
\hline 0 & 0 & 0.05 & 190 & 2.3 & 1.00 & 1.00 & 0.90 \\
\hline 0 & 1 & 0.05 & 210 & 3.3 & 1.11 & 1.43 & 0.88 \\
\hline 0 & 2 & 0.05 & 278 & 3.5 & 1.46 & 1.52 & 0.99 \\
\hline 0 & 3 & 0.05 & 320 & 4.2 & 1.68 & 1.83 & 0.92 \\
\hline 0 & 4 & 0.05 & 330 & 5 & 1.74 & 2.17 & 0.90 \\
\hline 0 & 0 & 0.1 & 152 & 2.5 & 1.00 & 1.00 & 0.72 \\
\hline 0 & 1 & 0.1 & 190 & 2.6 & 1.25 & 1.04 & 0.79 \\
\hline 0 & 2 & 0.1 & 252 & 2.8 & 1.66 & 1.12 & 0.89 \\
\hline 0 & 3 & 0.1 & 298 & 4 & 1.96 & 1.60 & 0.86 \\
\hline 0 & 4 & 0.1 & 308 & 4.5 & 2.03 & 1.80 & 0.84 \\
\hline 0 & 0 & 0.15 & 138 & 2.2 & 1.02 & 1.00 & 0.65 \\
\hline 0 & 1 & 0.15 & 171 & 2.3 & 1.27 & 1.05 & 0.71 \\
\hline 0 & 2 & 0.15 & 240 & 2.5 & 1.78 & 1.14 & 0.85 \\
\hline 0 & 3 & 0.15 & 255 & 3.8 & 1.89 & 1.73 & 0.73 \\
\hline 0 & 4 & 0.15 & 290 & 4.2 & 2.15 & 1.91 & 0.79 \\
\hline 0.5 & 0 & 0 & 330 & 1.4 & 1.00 & 1.00 & 1.00 \\
\hline 0.5 & 1 & 0 & 370 & 3.8 & 1.12 & 2.71 & 1.00 \\
\hline
\end{tabular}

\begin{tabular}{|c|c|c|c|c|c|c|c|}
\hline$D_{f} / \mathrm{B}$ & $\alpha^{0}$ & $N$ & $\overline{q_{u}}$ & $S_{u}$ & $B C R$ & $S R$ & $\frac{q_{u(e-i)}}{q_{u(e-i=0)}}$ \\
\hline 0.5 & 2 & 0 & 400 & 4 & 1.21 & 2.86 & 1.00 \\
\hline 0.5 & 3 & 0 & 450 & 4.2 & 1.36 & 3.00 & 1.00 \\
\hline 0.5 & 4 & 0 & 470 & 5 & 1.42 & 3.57 & 1.00 \\
\hline 0.5 & 0 & 0.05 & 310 & 1.3 & 1.00 & 1.00 & 0.94 \\
\hline 0.5 & 1 & 0.05 & 360 & 2.8 & 1.16 & 2.15 & 0.97 \\
\hline 0.5 & 2 & 0.05 & 390 & 3.7 & 1.26 & 2.85 & 0.98 \\
\hline 0.5 & 3 & 0.05 & 420 & 4 & 1.35 & 3.08 & 0.93 \\
\hline 0.5 & 4 & 0.05 & 460 & 5 & 1.48 & 3.85 & 0.98 \\
\hline 0.5 & 0 & 0.1 & 262 & 1.3 & 1.00 & 1.00 & 0.79 \\
\hline 0.5 & 1 & 0.1 & 322 & 1.5 & 1.23 & 1.15 & 0.87 \\
\hline 0.5 & 2 & 0.1 & 352 & 2.1 & 1.34 & 1.62 & 0.88 \\
\hline 0.5 & 3 & 0.1 & 365 & 3 & 1.39 & 2.31 & 0.81 \\
\hline 0.5 & 4 & 0.1 & 400 & 3.2 & 1.53 & 2.46 & 0.85 \\
\hline 0.5 & 0 & 0.15 & 250 & 1 & 1.00 & 1.00 & 0.76 \\
\hline 0.5 & 1 & 0.15 & 302 & 1.5 & 1.21 & 1.50 & 0.82 \\
\hline 0.5 & 2 & 0.15 & 320 & 2 & 1.28 & 2.00 & 0.80 \\
\hline 0.5 & 3 & 0.15 & 332 & 2.7 & 1.33 & 2.70 & 0.74 \\
\hline 0.5 & 4 & 0.15 & 372 & 2.8 & 1.49 & 2.80 & 0.79 \\
\hline 1 & 0 & 0 & 400 & 3.2 & 1.00 & 1.00 & 1.00 \\
\hline 1 & 1 & 0 & 460 & 6 & 1.12 & 1.88 & 1.00 \\
\hline 1 & 2 & 0 & 510 & 7 & 1.24 & 2.19 & 1.00 \\
\hline 1 & 3 & 0 & 540 & 7.5 & 1.32 & 2.34 & 1.00 \\
\hline
\end{tabular}


Table 2: Results of eccentrically loaded $(e / L)$ rectangular footing in unreinforced and reinforced sand conditions.

\begin{tabular}{llllllll}
\hline $\boldsymbol{D}_{f} / \mathbf{B}$ & $\boldsymbol{\alpha}^{\mathbf{0}}$ & $\boldsymbol{N}$ & $\boldsymbol{q}_{u}$ & $\boldsymbol{S}_{u}$ & $\boldsymbol{B C R}$ & $\boldsymbol{S R}$ & $\frac{q_{u(e-i)}}{q_{u(e-i=0)}}$ \\
\hline 1 & 4 & 0 & 580 & 8.5 & 1.41 & 2.66 & 1.04 \\
1 & 0 & 0.05 & 398 & 3.1 & 1.00 & 1.00 & 0.97 \\
1 & 1 & 0.05 & 440 & 5 & 1.11 & 1.61 & 0.96 \\
1 & 2 & 0.05 & 480 & 5.2 & 1.21 & 1.68 & 0.94 \\
1 & 3 & 0.05 & 500 & 6 & 1.26 & 1.94 & 0.93 \\
1 & 4 & 0.05 & 560 & 8 & 1.41 & 2.58 & 0.64 \\
1 & 0 & 0.1 & 360 & 2.1 & 1.00 & 1.00 & 0.88 \\
1 & 1 & 0.1 & 410 & 2.8 & 1.14 & 1.33 & 0.89 \\
\hline
\end{tabular}

\begin{tabular}{llllllll}
\hline $\boldsymbol{D}_{f} / \mathbf{B}$ & $\boldsymbol{\alpha}^{\mathbf{0}}$ & $\boldsymbol{N}$ & $\boldsymbol{q}_{u}$ & $\boldsymbol{S}_{u}$ & $\boldsymbol{B C R}$ & $\boldsymbol{S R}$ & $\frac{q_{u(e-i)}}{q_{u(e-i=0)}}$ \\
\hline 1 & 2 & 0.1 & 428 & 4.2 & 1.19 & 2.00 & 0.84 \\
1 & 3 & 0.1 & 470 & 4.5 & 1.31 & 2.14 & 0.87 \\
1 & 4 & 0.1 & 510 & 6 & 1.42 & 2.86 & 0.91 \\
1 & 0 & 0.15 & 310 & 1.5 & 1.00 & 1.00 & 0.76 \\
1 & 1 & 0.15 & 380 & 2.5 & 1.23 & 1.67 & 0.83 \\
1 & 2 & 0.15 & 400 & 2.8 & 1.29 & 1.87 & 0.78 \\
1 & 3 & 0.15 & 420 & 3.5 & 1.35 & 2.33 & 0.78 \\
1 & 4 & 0.15 & 480 & 4.5 & 1.55 & 3.00 & 0.86 \\
\hline
\end{tabular}

Table 3: Results of eccentrically loaded $(e / B)$ rectangular footing in unreinforced and reinforced sand conditions.

\begin{tabular}{|c|c|c|c|c|c|c|c|}
\hline$\overline{D_{f} / \mathrm{B}}$ & $\alpha^{0}$ & $N$ & $\overline{q_{u}}$ & $S_{u}$ & $B C R$ & $S R$ & $\frac{q_{u(e-i)}}{q_{u(e-i=0)}}$ \\
\hline 0 & 0 & 0 & 212 & 2.2 & 1.00 & 1.00 & 1.00 \\
\hline 0 & 1 & 0 & 240 & 3.8 & 1.13 & 1.73 & 1.00 \\
\hline 0 & 2 & 0 & 282 & 4.1 & 1.33 & 1.86 & 1.00 \\
\hline 0 & 3 & 0 & 348 & 4.7 & 1.64 & 2.14 & 1.00 \\
\hline 0 & 4 & 0 & 368 & 6 & 1.74 & 2.73 & 1.00 \\
\hline 0 & 0 & 0.05 & 180 & 2.2 & 1.00 & 1.00 & 0.85 \\
\hline 0 & 1 & 0.05 & 206 & 3.2 & 1.14 & 1.45 & 0.86 \\
\hline 0 & 2 & 0.05 & 270 & 3.5 & 1.50 & 1.59 & 0.96 \\
\hline 0 & 3 & 0.05 & 312 & 3.7 & 1.73 & 1.68 & 0.90 \\
\hline 0 & 4 & 0.05 & 325 & 4.5 & 1.81 & 2.05 & 0.88 \\
\hline 0 & 0 & 0.1 & 148 & 1.8 & 1.00 & 1.00 & 0.70 \\
\hline 0 & 1 & 0.1 & 160 & 2 & 1.08 & 1.11 & 0.67 \\
\hline 0 & 2 & 0.1 & 248 & 3 & 1.68 & 1.67 & 0.88 \\
\hline 0 & 3 & 0.1 & 270 & 3.2 & 1.82 & 1.78 & 0.78 \\
\hline 0 & 4 & 0.1 & 305 & 3.8 & 2.06 & 2.11 & 0.83 \\
\hline 0 & 0 & 0.15 & 132 & 1.2 & 1.00 & 1.00 & 0.00 \\
\hline 0 & 1 & 0.15 & 140 & 1.5 & 1.06 & 1.25 & 0.58 \\
\hline 0 & 2 & 0.15 & 232 & 2 & 1.76 & 1.67 & 0.82 \\
\hline 0 & 3 & 0.15 & 212 & 2.8 & 1.61 & 2.33 & 0.61 \\
\hline 0 & 4 & 0.15 & 280 & 3.3 & 2.12 & 2.75 & 0.76 \\
\hline 0.5 & 0 & 0 & 330 & 1.4 & 1.00 & 1.00 & 1.00 \\
\hline 0.5 & 1 & 0 & 370 & 3.8 & 1.12 & 2.71 & 1.00 \\
\hline 0.5 & 2 & 0 & 400 & 4 & 1.21 & 2.86 & 1.00 \\
\hline
\end{tabular}

\begin{tabular}{|c|c|c|c|c|c|c|c|}
\hline$D_{f} / B$ & $\alpha^{0}$ & $N$ & $q_{u}$ & $S_{u}$ & $B C R$ & $S R$ & $\frac{q_{u(e-i)}}{q_{u(e-i=0)}}$ \\
\hline 0.5 & 3 & 0 & 450 & 4.2 & 1.36 & 3.00 & 1.00 \\
\hline 0.5 & 4 & 0 & 470 & 5 & 1.42 & 3.57 & 1.00 \\
\hline 0.5 & 0 & 0.05 & 300 & 1.5 & 1.00 & 1.00 & 0.91 \\
\hline 0.5 & 1 & 0.05 & 338 & 2.8 & 1.13 & 1.87 & 0.91 \\
\hline 0.5 & 2 & 0.05 & 380 & 3 & 1.27 & 2.00 & 0.95 \\
\hline 0.5 & 3 & 0.05 & 400 & 4 & 1.33 & 2.67 & 0.89 \\
\hline 0.5 & 4 & 0.05 & 450 & 5 & 1.50 & 3.33 & 0.96 \\
\hline 0.5 & 0 & 0.1 & 258 & 1.3 & 1.00 & 1.00 & 0.78 \\
\hline 0.5 & 1 & 0.1 & 310 & 2.7 & 1.20 & 2.08 & 0.84 \\
\hline 0.5 & 2 & 0.1 & 342 & 2.9 & 1.33 & 2.23 & 0.86 \\
\hline 0.5 & 3 & 0.1 & 358 & 3.5 & 1.39 & 2.69 & 0.80 \\
\hline 0.5 & 4 & 0.1 & 380 & 3.8 & 1.47 & 2.92 & 0.81 \\
\hline 0.5 & 0 & 0.15 & 240 & 1 & 1.00 & 1.00 & 0.73 \\
\hline 0.5 & 1 & 0.15 & 280 & 1.5 & 1.17 & 1.50 & 0.76 \\
\hline 0.5 & 2 & 0.15 & 300 & 2.4 & 1.25 & 2.40 & 0.75 \\
\hline 0.5 & 3 & 0.15 & 328 & 2.6 & 1.37 & 2.60 & 0.73 \\
\hline 0.5 & 4 & 0.15 & 360 & 3 & 1.50 & 3.00 & 0.77 \\
\hline 1 & 0 & 0 & 400 & 3.2 & 1.00 & 1.00 & 1.00 \\
\hline 1 & 1 & 0 & 460 & 6 & 1.12 & 1.88 & 1.00 \\
\hline 1 & 2 & 0 & 510 & 7 & 1.24 & 2.19 & 1.00 \\
\hline 1 & 3 & 0 & 540 & 7.5 & 1.32 & 2.34 & 1.00 \\
\hline 1 & 4 & 0 & 580 & 8.5 & 1.41 & 2.66 & 1.04 \\
\hline 1 & 0 & 0.05 & 390 & 2 & 1.00 & 1.00 & 0.95 \\
\hline
\end{tabular}


Table 3: Results of eccentrically loaded $(e / B)$ rectangular footing in unreinforced and reinforced sand conditions.

\begin{tabular}{llllllll}
\hline $\boldsymbol{D}_{f} / \mathbf{B}$ & $\boldsymbol{\alpha}^{\mathbf{0}}$ & $\boldsymbol{N}$ & $\boldsymbol{q}_{u}$ & $\boldsymbol{S}_{u}$ & $\boldsymbol{B C R}$ & $\boldsymbol{S R}$ & $\frac{q_{u(e-i)}}{q_{u(e-i=0)}}$ \\
\hline 1 & 1 & 0.05 & 430 & 3 & 1.10 & 1.50 & 0.93 \\
1 & 2 & 0.05 & 470 & 4.8 & 1.21 & 2.40 & 0.92 \\
1 & 3 & 0.05 & 490 & 5.1 & 1.26 & 2.55 & 0.91 \\
1 & 4 & 0.05 & 550 & 6.2 & 1.41 & 3.10 & 0.98 \\
1 & 0 & 0.1 & 342 & 1.4 & 1.00 & 1.00 & 0.83 \\
1 & 1 & 0.1 & 400 & 2.4 & 1.17 & 1.71 & 0.87 \\
1 & 2 & 0.1 & 420 & 3.1 & 1.23 & 2.21 & 0.82 \\
\hline
\end{tabular}

\begin{tabular}{llllllll}
\hline $\boldsymbol{D}_{f} / \mathbf{B}$ & $\boldsymbol{\alpha}^{\circ}$ & $\boldsymbol{N}$ & $\boldsymbol{q}_{u}$ & $\boldsymbol{S}_{u}$ & $\boldsymbol{B C R}$ & $\boldsymbol{S R}$ & $\frac{q_{u(e-i)}}{q_{u(e-i=0)}}$ \\
\hline 1 & 3 & 0.1 & 450 & 3.4 & 1.32 & 2.43 & 0.83 \\
1 & 4 & 0.1 & 500 & 6 & 1.46 & 4.29 & 0.89 \\
1 & 0 & 0.15 & 302 & 1.1 & 1.00 & 1.00 & 0.74 \\
1 & 1 & 0.15 & 362 & 2.4 & 1.20 & 2.18 & 0.79 \\
1 & 2 & 0.15 & 385 & 2.8 & 1.27 & 2.55 & 0.75 \\
1 & 3 & 0.15 & 400 & 2.9 & 1.32 & 2.64 & 0.74 \\
1 & 4 & 0.15 & 460 & 3.5 & 1.52 & 3.18 & 0.82 \\
\hline
\end{tabular}

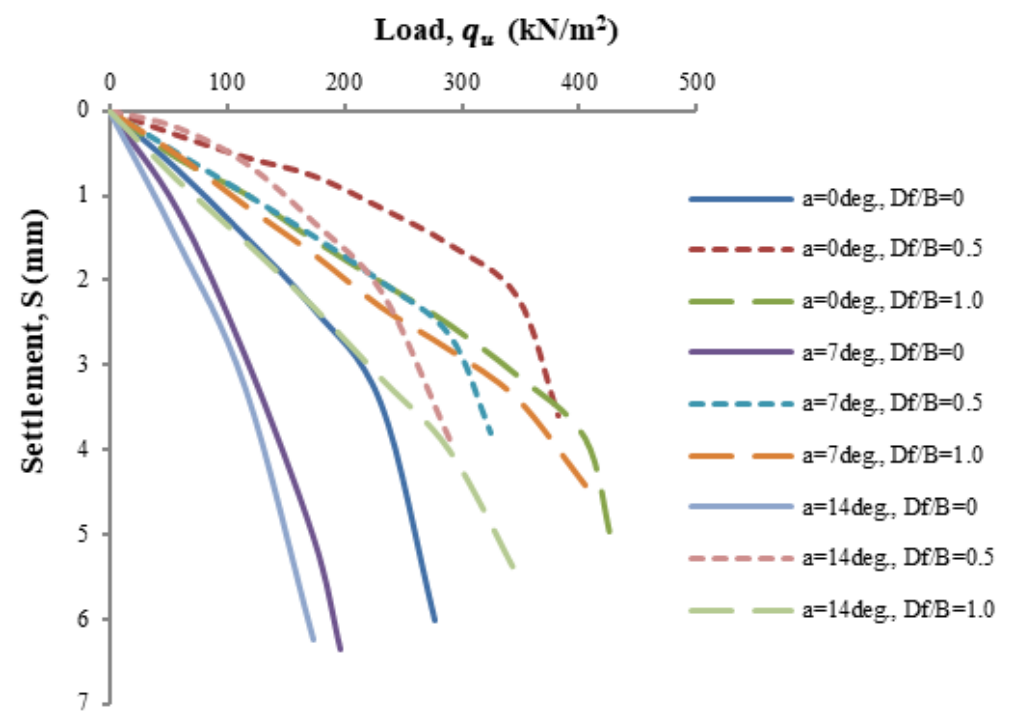

Figure 6(b): Variation of L-S curve for inclined loading with an embedment depth $D_{f} / B$.

\subsubsection{Effect of eccentrically inclined loading}

The load-settlement curve for different eccentric-inclined loading in both dimensions is shown in Fig. 6(c). These results indicate that the value of $q_{u}$ reduces with an increase in the load eccentricity and inclination of applied load in both dimensions. While the load eccentricity rises from 0 to 0.15 the value of $q_{u}$ reduces about 33\% and 31\% in the larger and smaller dimensions of the foundation, and when it applies on inclined load $0^{\circ}$ to $14^{\circ}$ the value of $q_{u}$ reduces about $48 \%$. The main reason for decreases in the UBC in the case of eccentric loading is that the contact pressure of the footing increases on the side of eccentricity and reduces on another side, resulting from the model footing tilt on the side of eccentricity. When the vertical pressure reaches the ultimate value, there will be a failure of the supporting soil on the side of eccentricity. Similarly, in the case of incline load, the contact pressure on the model foundation is not equally distributed. As a result, the footing loses contact with supporting soil and the UBC reduces. The results of theoretical solutions are presented in Tables 5 and 6 for both dimensions. It can be concluded that, by increasing the eccentrically inclined load, $B C R$ and $S R$ decreases. Thus, when the reinforcement layers are placed in optimum number $(N=3)$ for eccentricity and eccentrically inclined load, the $B C R$ reaches the maximum value, and after that if the number of reinforced layers are increased, this factor decreases.

\subsubsection{Effects of the number of reinforcement layers}

The load-settlement curve for different embedded model footing with multiple layers of the geogrid reinforcement at 
Table 4: Results of rectangular footing subjected to inclined loading $\left(\mathrm{a}^{\circ}\right)$ in unreinforced and reinforced sand conditions.

\begin{tabular}{|c|c|c|c|c|c|c|c|}
\hline $\bar{D} D_{f} / \mathrm{B}$ & $\alpha^{0}$ & $N$ & $\boldsymbol{q}_{u}$ & $S_{u}$ & $B C R$ & $S R$ & $q_{u(e-i)}$ \\
\hline & & & & & & & $q_{u(e-i=0)}$ \\
\hline 0 & 0 & 0 & 212 & 2.2 & 1.00 & 1.00 & 1.00 \\
\hline 0 & 0 & 1 & 240 & 3.8 & 1.13 & 1.73 & 1.00 \\
\hline 0 & 0 & 2 & 282 & 4.1 & 1.33 & 1.86 & 1.00 \\
\hline 0 & 0 & 3 & 348 & 4.7 & 1.64 & 2.14 & 1.00 \\
\hline 0 & 0 & 4 & 368 & 6 & 1.74 & 2.73 & 1.00 \\
\hline 0 & 7 & 0 & 134 & 2.8 & 1.00 & 1.00 & 0.63 \\
\hline 0 & 7 & 1 & 222 & 3.4 & 1.66 & 1.21 & 0.93 \\
\hline 0 & 7 & 2 & 240 & 3.8 & 1.79 & 1.36 & 0.85 \\
\hline 0 & 7 & 3 & 280 & 4 & 2.09 & 1.43 & 0.80 \\
\hline 0 & 7 & 4 & 310 & 4.5 & 2.31 & 1.61 & 0.84 \\
\hline 0 & 14 & 0 & 110 & 1.7 & 1.00 & 1.00 & 0.52 \\
\hline 0 & 14 & 1 & 154 & 2.4 & 1.40 & 1.41 & 0.64 \\
\hline 0 & 14 & 2 & 224 & 3 & 2.04 & 1.76 & 0.79 \\
\hline 0 & 14 & 3 & 268 & 4.1 & 2.44 & 2.41 & 0.77 \\
\hline 0 & 14 & 4 & 282 & 4.3 & 2.56 & 2.53 & 0.77 \\
\hline 0.5 & 0 & 0 & 330 & 1.4 & 1.00 & 1.00 & 1.00 \\
\hline 0.5 & 0 & 1 & 370 & 3.8 & 1.12 & 2.71 & 1.00 \\
\hline 0.5 & 0 & 2 & 400 & 4 & 1.21 & 2.86 & 1.00 \\
\hline 0.5 & 0 & 3 & 450 & 4.2 & 1.36 & 3.00 & 1.00 \\
\hline 0.5 & 0 & 4 & 470 & 5 & 1.42 & 3.57 & 1.00 \\
\hline 0.5 & 7 & 0 & 270 & 1.7 & 1.00 & 1.00 & 0.82 \\
\hline 0.5 & 7 & 1 & 300 & 2.5 & 1.11 & 1.47 & 0.81 \\
\hline 0.5 & 7 & 2 & 350 & 3 & 1.30 & 1.76 & 0.88 \\
\hline
\end{tabular}

\begin{tabular}{|c|c|c|c|c|c|c|c|}
\hline$D_{f} / \mathrm{B}$ & $\alpha^{0}$ & $N$ & $\boldsymbol{q}_{u}$ & $\boldsymbol{S}_{u}$ & $B C R$ & $S R$ & $\frac{q_{u(e-i)}}{q_{u(e-i=0)}}$ \\
\hline 0.5 & 7 & 3 & 400 & 3.5 & 1.48 & 2.06 & 0.89 \\
\hline 0.5 & 7 & 4 & 422 & 4 & 1.56 & 2.35 & 0.90 \\
\hline 0.5 & 14 & 0 & 195 & 1.2 & 1.00 & 1.00 & 0.59 \\
\hline 0.5 & 14 & 1 & 232 & 1.5 & 1.19 & 1.25 & 0.63 \\
\hline 0.5 & 14 & 2 & 300 & 2.5 & 1.54 & 2.08 & 0.75 \\
\hline 0.5 & 14 & 3 & 340 & 2.6 & 1.74 & 2.17 & 0.76 \\
\hline 0.5 & 14 & 4 & 360 & 4 & 1.85 & 3.33 & 0.77 \\
\hline 1 & 0 & 0 & 400 & 3.2 & 1.00 & 1.00 & 1.00 \\
\hline 1 & 0 & 1 & 460 & 6 & 1.12 & 1.88 & 1.00 \\
\hline 1 & 0 & 2 & 510 & 7 & 1.24 & 2.19 & 1.00 \\
\hline 1 & 0 & 3 & 540 & 7.5 & 1.32 & 2.34 & 1.00 \\
\hline 1 & 0 & 4 & 580 & 8.5 & 1.41 & 2.66 & 1.04 \\
\hline 1 & 7 & 0 & 350 & 3.2 & 1.00 & 1.00 & 0.85 \\
\hline 1 & 7 & 1 & 385 & 4.1 & 1.10 & 1.28 & 0.84 \\
\hline 1 & 7 & 2 & 455 & 4.4 & 1.30 & 1.38 & 0.89 \\
\hline 1 & 7 & 3 & 490 & 6.12 & 1.40 & 1.91 & 0.91 \\
\hline 1 & 7 & 4 & 520 & 6.98 & 1.49 & 2.18 & 0.93 \\
\hline 1 & 14 & 0 & 270 & 3 & 1.00 & 1.00 & 0.66 \\
\hline 1 & 14 & 1 & 322 & 3.2 & 1.19 & 1.07 & 0.70 \\
\hline 1 & 14 & 2 & 390 & 3.5 & 1.44 & 1.17 & 0.76 \\
\hline 1 & 14 & 3 & 420 & 3.8 & 1.56 & 1.27 & 0.78 \\
\hline 1 & 14 & 4 & 430 & 5 & 1.59 & 1.67 & 0.77 \\
\hline
\end{tabular}

\section{Load, $\boldsymbol{q}_{u}\left(\mathrm{kN} / \mathrm{m}^{2}\right)$}

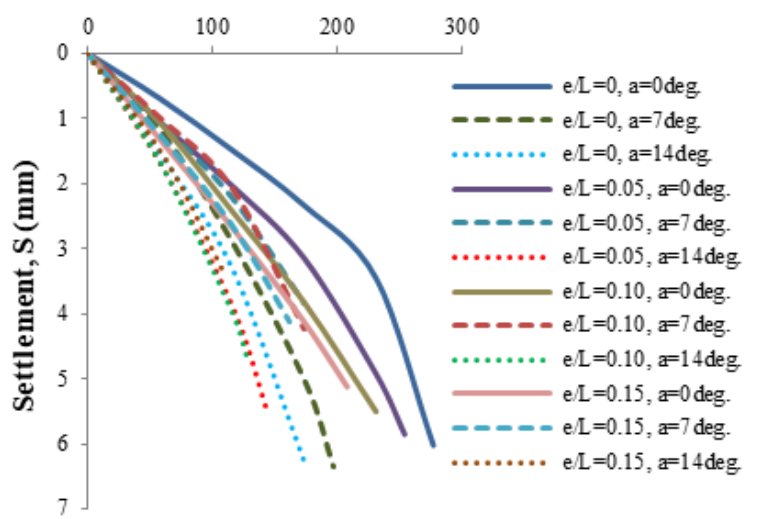

(a)
Load, $q_{u}\left(\mathrm{kN} / \mathrm{m}^{2}\right)$

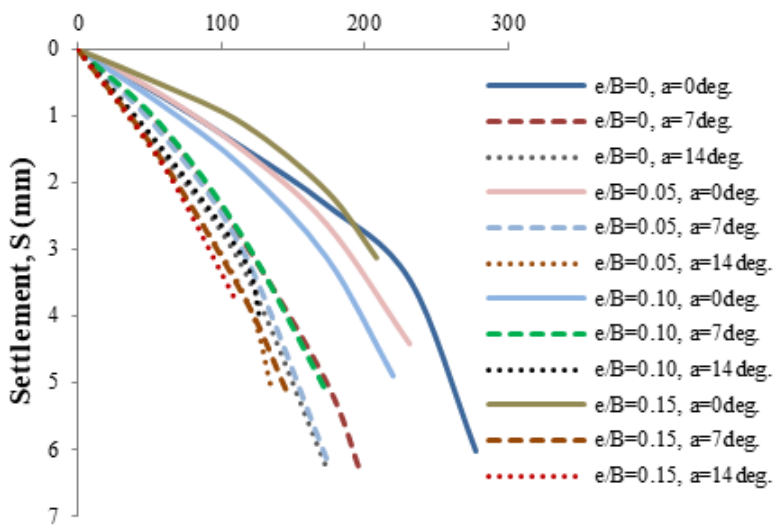

(b)

Figure 6(c): Variation of $\mathrm{L}-\mathrm{S}$ curve for $\left.D_{f} / B=0\right)$ at eccentric-inclined loading along with (a) larger dimension $(e / L$, a) and (b) smaller dimension $(e / B, a)$. 
Table 5: Results of eccentrically inclined, loaded $\left(\alpha^{\circ}, e / L\right)$ rectangular footing in unreinforced and reinforced sand conditions.

\begin{tabular}{|c|c|c|c|c|c|c|c|c|}
\hline$D_{f} / \mathrm{B}$ & $\alpha^{0}$ & $N$ & $e / B$ & $\boldsymbol{q}_{u}$ & $S_{u}$ & $B C R$ & $S R$ & $\frac{q_{u(e-i)}}{q_{u(e-i=0)}}$ \\
\hline 0 & 7 & 0 & 0.05 & 112 & 1.7 & 1.00 & 1.00 & 0.53 \\
\hline 0 & 7 & 1 & 0.05 & 190 & 3.2 & 1.70 & 1.88 & 0.79 \\
\hline 0 & 7 & 2 & 0.05 & 220 & 3.5 & 1.96 & 2.06 & 0.78 \\
\hline 0 & 7 & 3 & 0.05 & 242 & 3.8 & 2.16 & 2.24 & 0.70 \\
\hline 0 & 7 & 4 & 0.05 & 280 & 4.2 & 2.50 & 2.47 & 0.76 \\
\hline 0 & 7 & 0 & 0.1 & 106 & 1.6 & 1.00 & 1.00 & 0.50 \\
\hline 0 & 7 & 1 & 0.1 & 170 & 2.4 & 1.60 & 1.50 & 0.71 \\
\hline 0 & 7 & 2 & 0.1 & 185 & 3 & 1.75 & 1.88 & 0.66 \\
\hline 0 & 7 & 3 & 0.1 & 225 & 3.4 & 2.12 & 2.13 & 0.65 \\
\hline 0 & 7 & 4 & 0.1 & 252 & 3.7 & 2.38 & 2.31 & 0.68 \\
\hline 0 & 7 & 0 & 0.15 & 95 & 1.6 & 1.06 & 1.00 & 0.45 \\
\hline 0 & 7 & 1 & 0.15 & 155 & 2 & 1.72 & 1.25 & 0.65 \\
\hline 0 & 7 & 2 & 0.15 & 172 & 2.2 & 1.91 & 1.38 & 0.61 \\
\hline 0 & 7 & 3 & 0.15 & 202 & 2.5 & 2.24 & 1.56 & 0.58 \\
\hline 0 & 7 & 4 & 0.15 & 230 & 2.8 & 2.56 & 1.75 & 0.63 \\
\hline 0 & 14 & 0 & 0.05 & 100 & 1.4 & 1.00 & 1.00 & 0.47 \\
\hline 0 & 14 & 1 & 0.05 & 135 & 2 & 1.35 & 1.43 & 0.56 \\
\hline 0 & 14 & 2 & 0.05 & 220 & 2.5 & 2.20 & 1.79 & 0.78 \\
\hline 0 & 14 & 3 & 0.05 & 232 & 3 & 2.32 & 2.14 & 0.67 \\
\hline 0 & 14 & 4 & 0.05 & 245 & 3.7 & 2.45 & 2.64 & 0.67 \\
\hline 0 & 14 & 0 & 0.1 & 84 & 1.3 & 0.95 & 1.00 & 0.40 \\
\hline 0 & 14 & 1 & 0.1 & 122 & 1.5 & 1.39 & 1.15 & 0.51 \\
\hline 0 & 14 & 2 & 0.1 & 195 & 2 & 2.22 & 1.54 & 0.69 \\
\hline 0 & 14 & 3 & 0.1 & 228 & 2.5 & 2.59 & 1.92 & 0.66 \\
\hline 0 & 14 & 4 & 0.1 & 231 & 2.7 & 2.63 & 2.08 & 0.63 \\
\hline 0 & 14 & 0 & 0.15 & 76 & 1.2 & 1.00 & 1.00 & 0.36 \\
\hline 0 & 14 & 1 & 0.15 & 102 & 1.3 & 1.34 & 1.08 & 0.43 \\
\hline 0 & 14 & 2 & 0.15 & 180 & 1.8 & 2.37 & 1.50 & 0.64 \\
\hline 0 & 14 & 3 & 0.15 & 200 & 2.1 & 2.63 & 1.75 & 0.57 \\
\hline 0 & 14 & 4 & 0.15 & 210 & 2.3 & 2.76 & 1.92 & 0.57 \\
\hline 0.5 & 7 & 0 & 0.05 & 258 & 1.3 & 1.00 & 1.00 & 0.78 \\
\hline 0.5 & 7 & 1 & 0.05 & 282 & 2 & 1.09 & 1.54 & 0.76 \\
\hline 0.5 & 7 & 2 & 0.05 & 331 & 2.5 & 1.28 & 1.92 & 0.83 \\
\hline 0.5 & 7 & 3 & 0.05 & 370 & 2.6 & 1.43 & 2.00 & 0.82 \\
\hline 0.5 & 7 & 4 & 0.05 & 400 & 3.8 & 1.55 & 2.92 & 0.85 \\
\hline
\end{tabular}

\begin{tabular}{|c|c|c|c|c|c|c|c|c|}
\hline$D_{f} / \mathrm{B}$ & $\alpha^{\circ}$ & $N$ & $e / B$ & $q_{u}$ & $\boldsymbol{S}_{u}$ & $B C R$ & $S R$ & $\frac{q_{u(e-i)}}{q_{u(e-i=0)}}$ \\
\hline 0.5 & 7 & 0 & 0.1 & 221 & 1.2 & 1.00 & 1.00 & 0.67 \\
\hline 0.5 & 7 & 1 & 0.1 & 242 & 1.5 & 1.10 & 1.25 & 0.65 \\
\hline 0.5 & 7 & 2 & 0.1 & 310 & 2.4 & 1.40 & 2.00 & 0.78 \\
\hline 0.5 & 7 & 3 & 0.1 & 340 & 2.5 & 1.54 & 2.08 & 0.76 \\
\hline 0.5 & 7 & 4 & 0.1 & 360 & 2.8 & 1.63 & 2.33 & 0.77 \\
\hline 0.5 & 7 & 0 & 0.15 & 208 & 0.98 & 1.04 & 1.00 & 0.63 \\
\hline 0.5 & 7 & 1 & 0.15 & 220 & 1.1 & 1.10 & 1.12 & 0.59 \\
\hline 0.5 & 7 & 2 & 0.15 & 270 & 1.4 & 1.35 & 1.43 & 0.68 \\
\hline 0.5 & 7 & 3 & 0.15 & 290 & 1.6 & 1.45 & 1.63 & 0.64 \\
\hline 0.5 & 7 & 4 & 0.15 & 320 & 2 & 1.60 & 2.04 & 0.68 \\
\hline 0.5 & 14 & 0 & 0.05 & 188 & 0.98 & 1.00 & 1.00 & 0.57 \\
\hline 0.5 & 14 & 1 & 0.05 & 225 & 1.1 & 1.20 & 1.12 & 0.61 \\
\hline 0.5 & 14 & 2 & 0.05 & 285 & 1.8 & 1.52 & 1.84 & 0.71 \\
\hline 0.5 & 14 & 3 & 0.05 & 300 & 2.3 & 1.60 & 2.35 & 0.67 \\
\hline 0.5 & 14 & 4 & 0.05 & 320 & 2.8 & 1.70 & 2.86 & 0.68 \\
\hline 0.5 & 14 & 0 & 0.1 & 178 & 0.9 & 1.00 & 1.00 & 0.54 \\
\hline 0.5 & 14 & 1 & 0.1 & 200 & 1 & 1.12 & 1.11 & 0.54 \\
\hline 0.5 & 14 & 2 & 0.1 & 250 & 1.4 & 1.40 & 1.56 & 0.63 \\
\hline 0.5 & 14 & 3 & 0.1 & 280 & 1.6 & 1.57 & 1.78 & 0.62 \\
\hline 0.5 & 14 & 4 & 0.1 & 290 & 2.7 & 1.63 & 3.00 & 0.62 \\
\hline 0.5 & 14 & 0 & 0.15 & 160 & 0.7 & 1.00 & 1.00 & 0.48 \\
\hline 0.5 & 14 & 1 & 0.15 & 170 & 0.8 & 1.06 & 1.14 & 0.46 \\
\hline 0.5 & 14 & 2 & 0.15 & 220 & 1.3 & 1.38 & 1.86 & 0.55 \\
\hline 0.5 & 14 & 3 & 0.15 & 250 & 1.4 & 1.56 & 2.00 & 0.56 \\
\hline 0.5 & 14 & 4 & 0.15 & 270 & 1.6 & 1.69 & 2.29 & 0.57 \\
\hline 1 & 7 & 0 & 0.05 & 340 & 1.6 & 1.00 & 1.00 & 0.83 \\
\hline 1 & 7 & 1 & 0.05 & 360 & 3.2 & 1.06 & 2.00 & 0.78 \\
\hline 1 & 7 & 2 & 0.05 & 440 & 4 & 1.29 & 2.50 & 0.86 \\
\hline 1 & 7 & 3 & 0.05 & 460 & 4.62 & 1.35 & 2.89 & 0.85 \\
\hline 1 & 7 & 4 & 0.05 & 480 & 5 & 1.41 & 3.13 & 0.86 \\
\hline 1 & 7 & 0 & 0.1 & 300 & 1.6 & 1.00 & 1.00 & 0.73 \\
\hline 1 & 7 & 1 & 0.1 & 320 & 3 & 1.07 & 1.88 & 0.70 \\
\hline 1 & 7 & 2 & 0.1 & 390 & 3.2 & 1.30 & 2.00 & 0.76 \\
\hline 1 & 7 & 3 & 0.1 & 420 & 3.9 & 1.40 & 2.44 & 0.78 \\
\hline 1 & 7 & 4 & 0.1 & 430 & 4.2 & 1.43 & 2.63 & 0.77 \\
\hline
\end{tabular}


Table 5: Results of eccentrically inclined, loaded $\left(\alpha^{\circ}, e / L\right)$ rectangular footing in unreinforced and reinforced sand conditions.

\begin{tabular}{lllllllll}
\hline $\boldsymbol{D}_{f} / \mathbf{B}$ & $\boldsymbol{\alpha}^{\mathbf{0}}$ & $\boldsymbol{N}$ & $\boldsymbol{e} / \boldsymbol{B}$ & $\boldsymbol{q}_{u}$ & $\boldsymbol{S}_{u}$ & $\boldsymbol{B C R}$ & $\boldsymbol{S R}$ & $\frac{q_{u(e-i)}}{q_{u(e-i=0)}}$ \\
\hline 1 & 7 & 0 & 0.15 & 270 & 1 & 1.00 & 1.00 & 0.66 \\
1 & 7 & 1 & 0.15 & 290 & 2.5 & 1.07 & 2.50 & 0.63 \\
1 & 7 & 2 & 0.15 & 340 & 2.8 & 1.26 & 2.80 & 0.67 \\
1 & 7 & 3 & 0.15 & 380 & 3.1 & 1.41 & 3.10 & 0.70 \\
1 & 7 & 4 & 0.15 & 395 & 3.3 & 1.46 & 3.30 & 0.71 \\
1 & 14 & 1 & 0.05 & 290 & 2.8 & 1.12 & 1.12 & 0.63 \\
1 & 14 & 2 & 0.05 & 372 & 3 & 1.43 & 1.20 & 0.73 \\
1 & 14 & 3 & 0.05 & 390 & 3.4 & 1.50 & 1.36 & 0.72 \\
1 & 14 & 4 & 0.05 & 400 & 3.6 & 1.54 & 1.44 & 0.71 \\
1 & 14 & 0 & 0.1 & 242 & 1.5 & 1.00 & 1.00 & 0.59 \\
\hline
\end{tabular}

centric vertical loading is shown in Fig. 7. From the graphs, it can be seen that the value of UBC of model footing increases with an increase in the depth of embedment and the settlement of the model foundation also increases with the same. These figures also indicate that the value of UBC increases with the increasing numbers of reinforcing layers at any depth of embedment $\left(D_{f} / B\right)$.

These figures also indicate that the value of UBC increases with increasing the numbers of reinforcing layers. With the increase of the number of reinforcing layers in the contact area, the interlocking between sand particles and reinforcing layers are also increasing. Thus, the larger displacement and shear stresses are built up into the soil beneath the model foundation and transferred in reinforcement layers to the larger mass of soil. Therefore, the failure wedge becomes larger and the frictional resistance in failure planes become more [2].

\subsubsection{Effect of the number of geogrid layers}

This study aims to investigate the optimum number of geogrid layers to take the maximum benefit of soil reinforcement. The four layers of geogrid were adopted in the present study. The first layer of geogrid $\left(u_{r} / \mathrm{B}\right)$ was placed at a depth of $0.08 \mathrm{~m}$ beneath the model foundation and afterward, other layers of geogrid $\left(h_{r} / \mathrm{B}\right)$ were placed at $0.06 \mathrm{~m}$ depth. Fig. 8 showed the variation of UBC with several layers of geogrid ( $N=0$ to 4 ) in eccentrically loaded modeled footing in both dimensions. These figures clearly showed that the UBC increases at the third layer of reinforcement and after that, the rate of load increment becomes much less. This study concludes that $N=3$ is the

\begin{tabular}{lllllllll}
\hline $\boldsymbol{D}_{f} / \mathbf{B}$ & $\boldsymbol{\alpha}^{\mathbf{0}}$ & $\boldsymbol{N}$ & $\boldsymbol{e} / \boldsymbol{B}$ & $\boldsymbol{q}_{u}$ & $\boldsymbol{S}_{u}$ & $\boldsymbol{B C R}$ & $\boldsymbol{S R}$ & $\frac{q_{u(e-i)}}{q_{u(e-i=0)}}$ \\
\hline 1 & 14 & 1 & 0.1 & 270 & 1.8 & 1.12 & 1.20 & 0.59 \\
1 & 14 & 2 & 0.1 & 320 & 2 & 1.32 & 1.33 & 0.63 \\
1 & 14 & 3 & 0.1 & 360 & 2.5 & 1.49 & 1.67 & 0.67 \\
1 & 14 & 4 & 0.1 & 380 & 3 & 1.57 & 2.00 & 0.68 \\
1 & 14 & 0 & 0.15 & 198 & 1.2 & 1.00 & 1.00 & 0.48 \\
1 & 14 & 1 & 0.15 & 220 & 1.5 & 1.11 & 1.25 & 0.48 \\
1 & 14 & 2 & 0.15 & 270 & 1.8 & 1.36 & 1.50 & 0.53 \\
1 & 14 & 3 & 0.15 & 320 & 2 & 1.62 & 1.67 & 0.59 \\
1 & 14 & 4 & 0.15 & 350 & 2.1 & 1.77 & 1.75 & 0.63 \\
\hline
\end{tabular}

optimum number of the reinforcement layers, which was also present in prior studies of the strip and square footing over reinforced sand [4, 26]. These studies also showed that the optimum number of the soil reinforcement layer depends on the vertical spacing between geogrid layers and the embedment depth of the first layer. This is since the soil reinforcement would be significant when placed in an effective zone under the footing.

\section{Conclusions}

A series of laboratory tests were conducted to know the behaviour of the UBC of shallow rectangular foundation on unreinforced and multi-layered geogrid reinforced sand, under eccentric and inclined load with an embedment ratio varying from 0 to 1 . Only one type of sand at one average relative density of compaction was used for all the tests. The test sand was reinforced with multiple layers of the bi-axial geogrid which varied from 0 to 4 . The load eccentricity $(e / L, e / B)$ varied from 0 to 0.15 , and the inclination of applied load a varied from $0^{\circ}$ to $14^{\circ}$. The non-dimensional equations $B C R$ and $S R$ have been developed in Eqs (2) and (3). The following conclusions are drawn from the present study:

1. The value of UBC reduces about $33 \%$ and $31 \%$ with an increase in the load eccentricity 0 to 0.15 in both dimensions. Similarly, the reduction is in the range of $21 \%$ and $24 \%$ if the footing is placed over geogrid reinforced sand.

2. As the load inclination increases from $0^{\circ}$ to $14^{\circ}$, the UBC is decreased by $48 \%$. Similarly, this decrement 
Table 6: Results of eccentrically inclined, loaded $\left(\alpha^{\circ}, e / B\right)$ rectangular footing in unreinforced and reinforced sand conditions.

\begin{tabular}{|c|c|c|c|c|c|c|c|c|c|c|c|c|c|c|c|c|c|}
\hline$D_{f} / \mathrm{B}$ & $\alpha^{\circ}$ & $N$ & $e / B$ & $q_{u}$ & $\boldsymbol{S}_{u}$ & $B C R$ & $S R$ & $\frac{q_{u(e-i)}}{q_{u(e-i=0)}}$ & $\overline{D_{f} / \mathrm{B}}$ & $\alpha^{\circ}$ & $N$ & $e / B$ & $q_{u}$ & $\boldsymbol{S}_{u}$ & $B C R$ & $S R$ & $\frac{q_{u(e-i)}}{q_{u(e-i=0)}}$ \\
\hline 0 & 7 & 0 & 0.05 & 105 & 2.2 & 1.00 & 1.00 & 0.50 & 0.5 & 7 & 1 & 0.1 & 232 & 1.2 & 1.10 & 1.09 & 0.63 \\
\hline 0 & 7 & 1 & 0.05 & 180 & 3 & 1.71 & 1.36 & 0.75 & 0.5 & 7 & 2 & 0.1 & 300 & 1.7 & 1.43 & 1.55 & 0.75 \\
\hline 0 & 7 & 2 & 0.05 & 212 & 3.5 & 2.02 & 1.59 & 0.75 & 0.5 & 7 & 3 & 0.1 & 332 & 2.2 & 1.58 & 2.00 & 0.74 \\
\hline 0 & 7 & 3 & 0.05 & 232 & 4 & 2.21 & 1.82 & 0.67 & 0.5 & 7 & 4 & 0.1 & 320 & 3 & 1.52 & 2.73 & 0.68 \\
\hline 0 & 7 & 4 & 0.05 & 262 & 4.2 & 2.50 & 1.91 & 0.71 & 0.5 & 7 & 0 & 0.15 & 200 & 1 & 1.00 & 1.00 & 0.61 \\
\hline 0 & 7 & 0 & 0.1 & 99 & 1.9 & 1.00 & 1.00 & 0.47 & 0.5 & 7 & 1 & 0.15 & 210 & 1.1 & 1.05 & 1.10 & 0.64 \\
\hline 0 & 7 & 1 & 0.1 & 165 & 2.2 & 1.67 & 1.16 & 0.69 & 0.5 & 7 & 2 & 0.15 & 260 & 1.6 & 1.30 & 1.60 & 0.65 \\
\hline 0 & 7 & 2 & 0.1 & 178 & 2.5 & 1.80 & 1.32 & 0.63 & 0.5 & 7 & 3 & 0.15 & 278 & 1.8 & 1.39 & 1.80 & 0.62 \\
\hline 0 & 7 & 3 & 0.1 & 199 & 3 & 2.01 & 1.58 & 0.57 & 0.5 & 7 & 4 & 0.15 & 298 & 2 & 1.49 & 2.00 & 0.63 \\
\hline 0 & 7 & 4 & 0.1 & 232 & 3.2 & 2.34 & 1.68 & 0.63 & 0.5 & 14 & 0 & 0.05 & 185 & 1 & 1.00 & 1.00 & 0.56 \\
\hline 0 & 7 & 0 & 0.15 & 84 & 1.7 & 1.00 & 1.00 & 0.40 & 0.5 & 14 & 1 & 0.05 & 215 & 1.1 & 1.16 & 1.10 & 0.58 \\
\hline 0 & 7 & 1 & 0.15 & 152 & 1.9 & 1.81 & 1.12 & 0.63 & 0.5 & 14 & 2 & 0.05 & 282 & 1.5 & 1.52 & 1.50 & 0.71 \\
\hline 0 & 7 & 2 & 0.15 & 168 & 2.2 & 2.00 & 1.29 & 0.60 & 0.5 & 14 & 3 & 0.05 & 290 & 1.8 & 1.57 & 1.80 & 0.64 \\
\hline 0 & 7 & 3 & 0.15 & 175 & 2.8 & 2.08 & 1.65 & 0.50 & 0.5 & 14 & 4 & 0.05 & 310 & 2 & 1.68 & 2.00 & 0.66 \\
\hline 0 & 7 & 4 & 0.15 & 220 & 3.2 & 2.62 & 1.88 & 0.60 & 0.5 & 14 & 0 & 0.1 & 162 & 0.8 & 1.00 & 1.00 & 0.49 \\
\hline 0 & 14 & 0 & 0.05 & 98 & 1.2 & 1.00 & 1.00 & 0.46 & 0.5 & 14 & 1 & 0.1 & 189 & 0.9 & 1.17 & 1.13 & 0.51 \\
\hline 0 & 14 & 1 & 0.05 & 132 & 1.4 & 1.35 & 1.17 & 0.55 & 0.5 & 14 & 2 & 0.1 & 242 & 1.2 & 1.49 & 1.50 & 0.61 \\
\hline 0 & 14 & 2 & 0.05 & 210 & 2 & 2.14 & 1.67 & 0.74 & 0.5 & 14 & 3 & 0.1 & 270 & 1.4 & 1.67 & 1.75 & 0.60 \\
\hline 0 & 14 & 3 & 0.05 & 220 & 2.8 & 2.24 & 2.33 & 0.63 & 0.5 & 14 & 4 & 0.1 & 280 & 1.5 & 1.73 & 1.88 & 0.60 \\
\hline 0 & 14 & 4 & 0.05 & 242 & 2.9 & 2.47 & 2.42 & 0.66 & 0.5 & 14 & 0 & 0.15 & 152 & 0.6 & 1.00 & 1.00 & 0.46 \\
\hline 0 & 14 & 0 & 0.1 & 88 & 2 & 0.47 & 1.00 & 0.42 & 0.5 & 14 & 1 & 0.15 & 165 & 0.7 & 1.09 & 1.17 & 0.45 \\
\hline 0 & 14 & 1 & 0.1 & 120 & 1.2 & 0.64 & 0.60 & 0.50 & 0.5 & 14 & 2 & 0.15 & 210 & 0.9 & 1.38 & 1.50 & 0.53 \\
\hline 0 & 14 & 2 & 0.1 & 190 & 1.7 & 1.01 & 0.85 & 0.67 & 0.5 & 14 & 3 & 0.15 & 240 & 1.2 & 1.58 & 2.00 & 0.53 \\
\hline 0 & 14 & 3 & 0.1 & 201 & 2.5 & 1.07 & 1.25 & 0.58 & 0.5 & 14 & 4 & 0.15 & 255 & 1.4 & 1.68 & 2.33 & 0.54 \\
\hline 0 & 14 & 4 & 0.1 & 222 & 2.6 & 1.18 & 1.30 & 0.60 & 1 & 7 & 0 & 0.05 & 328 & 1.2 & 1.00 & 1.00 & 0.80 \\
\hline 0 & 14 & 0 & 0.15 & 64 & 1 & 1.00 & 1.00 & 0.30 & 1 & 7 & 1 & 0.05 & 344 & 2.5 & 1.05 & 2.08 & 0.75 \\
\hline 0 & 14 & 1 & 0.15 & 100 & 1.2 & 1.56 & 1.20 & 0.42 & 1 & 7 & 2 & 0.05 & 430 & 3 & 1.31 & 2.50 & 0.84 \\
\hline 0 & 14 & 2 & 0.15 & 170 & 1.5 & 2.66 & 1.50 & 0.60 & 1 & 7 & 3 & 0.05 & 450 & 5 & 1.37 & 4.17 & 0.83 \\
\hline 0 & 14 & 3 & 0.15 & 180 & 2 & 2.81 & 2.00 & 0.52 & 1 & 7 & 4 & 0.05 & 470 & 6.2 & 1.43 & 5.17 & 0.84 \\
\hline 0 & 14 & 4 & 0.15 & 201 & 2.1 & 3.14 & 2.10 & 0.55 & 1 & 7 & 0 & 0.1 & 290 & 1 & 1.00 & 1.00 & 0.71 \\
\hline 0.5 & 7 & 0 & 0.05 & 252 & 1.1 & 1.00 & 1.00 & 0.76 & 1 & 7 & 1 & 0.1 & 310 & 2.2 & 1.07 & 2.20 & 0.67 \\
\hline 0.5 & 7 & 1 & 0.05 & 270 & 1.4 & 1.07 & 1.27 & 0.73 & 1 & 7 & 2 & 0.1 & 380 & 2.5 & 1.31 & 2.50 & 0.75 \\
\hline 0.5 & 7 & 2 & 0.05 & 322 & 1.6 & 1.28 & 1.45 & 0.81 & 1 & 7 & 3 & 0.1 & 400 & 3.1 & 1.38 & 3.10 & 0.74 \\
\hline 0.5 & 7 & 3 & 0.05 & 360 & 2.5 & 1.43 & 2.27 & 0.80 & 1 & 7 & 4 & 0.1 & 420 & 3.4 & 1.45 & 3.40 & 0.75 \\
\hline 0.5 & 7 & 4 & 0.05 & 380 & 3 & 1.51 & 2.73 & 0.81 & 1 & 7 & 0 & 0.15 & 260 & 0.9 & 1.00 & 1.00 & 0.63 \\
\hline 0.5 & 7 & 0 & 0.1 & 210 & 1.1 & 1.00 & 1.00 & 0.64 & 1 & 7 & 1 & 0.15 & 282 & 1.5 & 1.08 & 1.67 & 0.61 \\
\hline
\end{tabular}


Table 6: Results of eccentrically inclined, loaded $\left(\alpha^{\circ}, e / B\right)$ rectangular footing in unreinforced and reinforced sand conditions.

\begin{tabular}{lllllllll}
\hline $\boldsymbol{D}_{f} / \mathbf{B}$ & $\boldsymbol{\alpha}^{\mathbf{0}}$ & $\boldsymbol{N}$ & $\boldsymbol{e} / \boldsymbol{B}$ & $\boldsymbol{q}_{u}$ & $\boldsymbol{S}_{u}$ & $\boldsymbol{B C R}$ & $\boldsymbol{S R}$ & $\frac{q_{u(e-i)}}{q_{u(e-i=0)}}$ \\
\hline 1 & 7 & 2 & 0.15 & 320 & 1.8 & 1.23 & 2.00 & 0.63 \\
1 & 7 & 3 & 0.15 & 360 & 2.5 & 1.38 & 2.78 & 0.67 \\
1 & 7 & 4 & 0.15 & 370 & 2.8 & 1.42 & 3.11 & 0.66 \\
1 & 14 & 0 & 0.05 & 255 & 1.7 & 1.00 & 1.00 & 0.62 \\
1 & 14 & 1 & 0.05 & 280 & 2.8 & 1.10 & 1.65 & 0.61 \\
1 & 14 & 2 & 0.05 & 362 & 3 & 1.42 & 1.76 & 0.71 \\
1 & 14 & 3 & 0.05 & 380 & 3.4 & 1.49 & 2.00 & 0.70 \\
1 & 14 & 4 & 0.05 & 390 & 4.5 & 1.53 & 2.65 & 0.70 \\
1 & 14 & 0 & 0.1 & 230 & 1.5 & 1.00 & 1.00 & 0.56 \\
\hline
\end{tabular}

\begin{tabular}{lllllllll}
\hline $\boldsymbol{D}_{f} / \mathbf{B}$ & $\boldsymbol{\alpha}^{\mathbf{0}}$ & $\boldsymbol{N}$ & $\boldsymbol{e} / \boldsymbol{B}$ & $\boldsymbol{q}_{u}$ & $\boldsymbol{S}_{u}$ & $\boldsymbol{B C R}$ & $\boldsymbol{S R}$ & $\frac{q_{u(e-i)}}{q_{u(e-i=0)}}$ \\
\hline 1 & 14 & 1 & 0.1 & 260 & 1.8 & 1.13 & 1.20 & 0.57 \\
1 & 14 & 2 & 0.1 & 305 & 2 & 1.33 & 1.33 & 0.60 \\
1 & 14 & 3 & 0.1 & 350 & 2.5 & 1.52 & 1.67 & 0.65 \\
1 & 14 & 4 & 0.1 & 360 & 3.4 & 1.57 & 2.27 & 0.64 \\
1 & 14 & 0 & 0.15 & 190 & 1.1 & 1.00 & 1.00 & 0.46 \\
1 & 14 & 1 & 0.15 & 210 & 1.4 & 1.11 & 1.27 & 0.46 \\
1 & 14 & 2 & 0.15 & 260 & 1.8 & 1.37 & 1.64 & 0.51 \\
1 & 14 & 3 & 0.15 & 310 & 2 & 1.63 & 1.82 & 0.57 \\
1 & 14 & 4 & 0.15 & 330 & 2.4 & 1.74 & 2.18 & 0.59 \\
\hline
\end{tabular}

\section{Load, $q_{u}\left(\mathrm{kN} / \mathrm{m}^{2}\right)$}

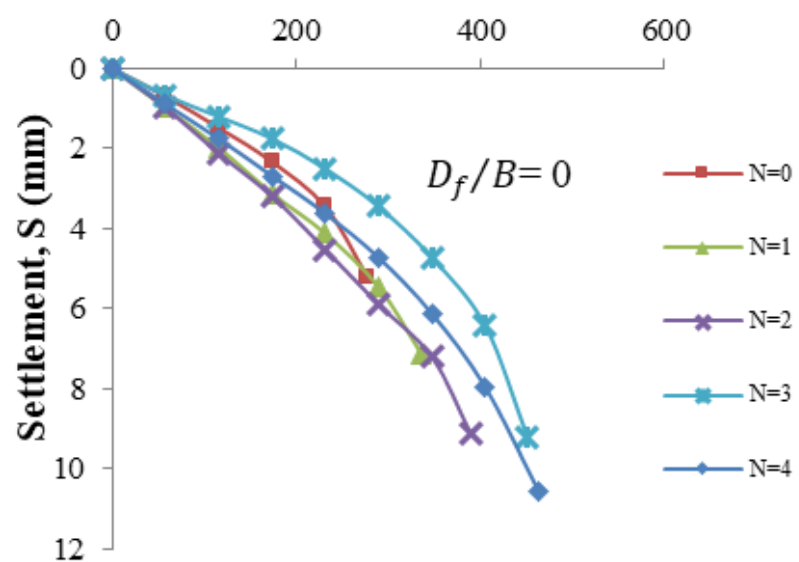

(a)

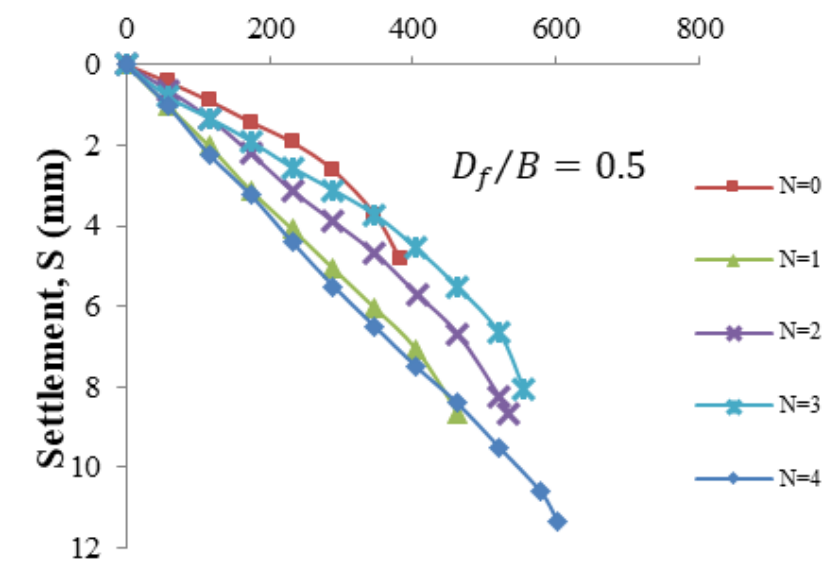

(b)

Load, $q_{u}\left(\mathrm{kN} / \mathrm{m}^{2}\right)$

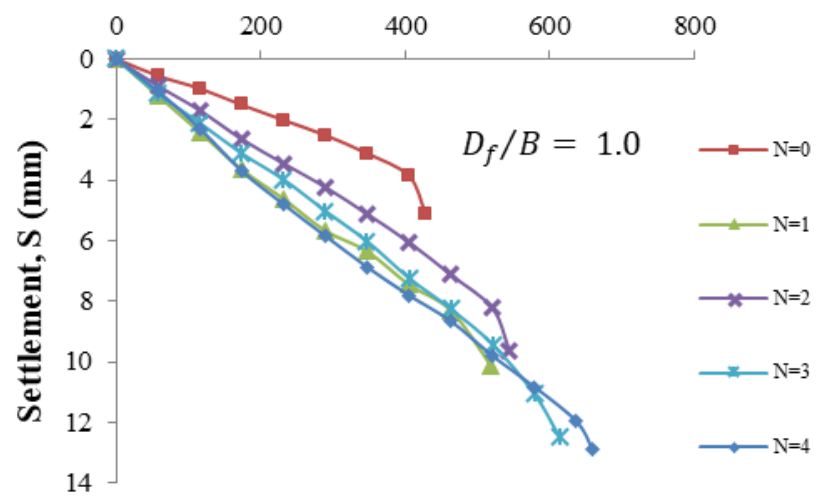

(c)

Figure 7: Variation of L-S curve with multiple layers of geogrid $N$ for (a) surface footing $D_{f} / B=0$, (b) embedded footing $D_{f} / B=0.5$, and (c) embedded footing $D_{f} / B=1.0$ at axial centric loading $(e=0, \alpha=0)$. 


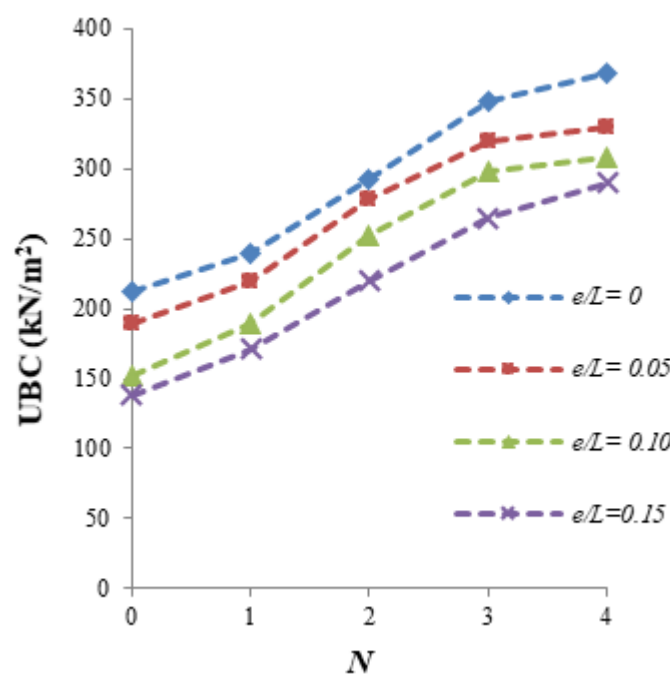

(a)

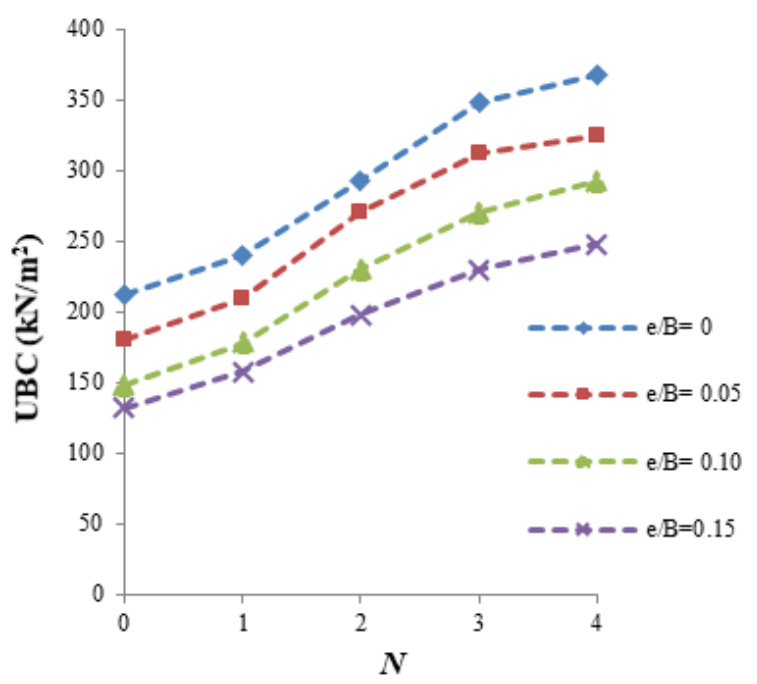

(b)

Figure 8: Variation of $B C R$ with Nat eccentric loading along the length and width side.

is in the range of $24 \%$ when the footing is placed on reinforced sand.

3. The value of UBC increases by about $75 \%$ with an increasing number of layers of geogrid reinforcement $(N=0$ to 4$)$.

4. The value of UBC increases by about $93 \%$ with an increasing the depth of embedded footing $\left(D_{f} / B=0\right.$ to 1).

5. The $B C R$ increases with an increase in the numbers of geogrid reinforcing layers in both dimensions of the model footing and it is decreased with increasing the eccentricity and eccentrically inclined loads.

6. The optimum layer of reinforcement is $N=3$ because the UBC increases at the third layer reinforcement and after that, the rate of load increment becomes much less.

Acknowledgment: The present work is supported financially through a Ph.D. scholarship grant (2K16/NITK/ PHD/6160052) by The Ministry of Human Resource and Development, Government of India.

Conflict of interest: The authors wish to confirm that there are no known conflicts of interest associated with this publication and there has been no significant financial support for this work that could have influenced its outcome.

\section{References}

[1] Badakhshan, E., Noorzad, A. (2015). Load eccentricity effects on the behaviour of circular footings reinforced with geogrid sheets, J Rock MechGeotechEng, 7, pp. 691-9. https://doi. org/10.1016/j.jrmge.2015.08.006

[2] Badakhshan, E., Noorzad, A. (2017). Effect of footing shape and load eccentricity on the behaviour of the geosynthetics reinforced sand bed, GeotextGeomemb, 45, pp. 58-67. https:// doi.org/10.1016/j.geotexmem.2016.11.007

[3] Behera, R.N. (2013). Behaviour of shallow strip foundation on granular soil under eccentrically inclined loads, Ph.D. Thesis, National Institute of Technology Rourkela, India.

[4] Boushehrian, J.H., Hataf, N. (2003). Experimental and numerical investigation of the bearing capacity of model circular and ring footing on reinforced sand, GeotextGeomemb, 21, pp. 241-256.

[5] Das, B.M., Omar, M.T. (1994). The effects of foundation width on model tests for the bearing capacity of sand with geogrid reinforcement, GeotechGeolEng, 12, pp. 133-141.

[6] Foye, K.C., Salgado, R., Scott, B. (2006). Assessment of variable uncertainties for the reliability-based design of the foundation, J Geo Geoenviron Eng., 131(9), pp. 1197-1207. https://doi.org/10.1061/(ASCE)1090-0241(2006)132:9 (1197)

[7] Ganesh, R., Khuntia, S., Sahoo, J.P. (2016). Bearing capacity of shallow strip footing in the sand under eccentric and oblique loads, Int J Geomech, 17(4), pp. 06016028. https://doi. org/10.1061/(ASCE)GM.1943-5622.0000799

[8] Guido, et al. (1986). Comparison of geogrid and geotextile reinforced earth slabs, Can Geotech J, 23(4), pp. 435-440.

[9] Hjiaj, M., Lyamin, A.V., Sloan, S.W. (2004). Bearing capacity of a cohesive-frictional soil under non-eccentric inclined loading, ComputGeotech. 31, pp. 491-516. https://doi.org/10.1016/j. compgeo.2004.06.001

[10] Krabbenhoft, S., Damkilde, L., Krabbenhoft, K. (2014). Bearing capacity of strip footings on cohesionless soils subjected to 
eccentric and inclined load, Int J Geomech, pp. 04014003-18 10.1061/(ASCE)GM.1943-5622.0000332,04014003

[11] Kumar, A., Ohri, M.L., Bansal, R.K. (2006). Bearing capacity test of strip footings on reinforced layered soil, GeotechGeolEng, 25, pp. 139-150. https://doi.org/10.1007/ s10706-006-0011-6

[12] Kumar, A., Walia, B.S. (2006). Bearing capacity of square footing on reinforced layered soil, J GeotechGeolEng, 24, pp. 1001-1008.

[13] Latha, G.M., Somwanshi, A. (2009). Bearing capacity of square footing on geosynthetic reinforced sand, GeotextGeomemb, 27, pp. 281-294. https://doi.org/10.1016/j. geotexmem.2009.02.001

[14] Loukidis, D., Salgado, R. (2009). Bearing capacity of the strip and circular footing in sand using finite element, ComputGeotech, 36, pp. 871-879. https://doi.org/10.1016/j. compgeo.2009.01.012

[15] Meyerhof, G.G. (1953). An Investigation for the Foundations of a Bridge on Dense Sand. Proceedings of the $3^{\text {rd }}$ International Conference on Soil Mechanics and Foundation Engineering, 2, pp. 66-70.

[16] Michalowski, R.L. (2004). Limit load on reinforced foundation soils, J GeotechGeoenvironEng, ASCE, 130(4), pp. 381-390.

[17] Nazir, A.K., Azzam, W.R. (2011). Improving the bearing capacity of footing soft clay with sand pile with / without skirt, Alex Eng J, 49, pp. 371-377. https://doi.org/10.1016/j.aej.2010.06.002

[18] Omar, et al. (1993). Ultimate bearing capacity of shallow foundation on sand with geogrid reinforcement, Can Geotech J, 30(3), pp. 545-549.

[19] Ornek, M. (2014). Estimation of ultimate loads of eccentricinclined loaded strip footing rested on sandy soils, Neural Computing \& Applications, 25, pp. 39-54. https://doi. org/10.1007/s00521-013-1444-5

[20] Padmini, D., Ilamparuthi, K.K., Sudheer, K.P. (2007). Ultimate bearing capacity of shallow foundations on cohesionless soil using neuro-fuzzy models, J ComputGeotech, 35(1), pp. 33-46. https://doi.org/10.1016/j.compgeo.2007.03.001

[21] Patra, C.R., Behera, R.N., Shivakugan, N., Das, B.M. (2012). Ultimate bearing capacity of shallow strip foundation under eccentrically inclined load Part-1. Int J Geotech Eng, 6.

[22] Patra, C.R., Das, B.M., Atalar, C. (2005). Bearing capacity of embedded strip foundation on geogrid-reinforced sand, GeotextGeomemb, 23, pp. 454-462.

[23] Patra, C.R., Das, B.M., Bhoi, M., Shin, E.C. (2006). Eccentricity loaded strip foundation on geogrid-reinforced sand, GeotextGeomemb, 24(4), pp. 254-259.

[24] Sadoglu, E., Cure, E., Moroglu, B., Uzuner, B.A. (2009) Ultimate loads for eccentrically loaded model shallow strip footings on geotextile-reinforced sand, GeotextGeomemb, 27(3), pp.17682.

[25] Sawwaf, E.l., Mostafa, A. (2007). Behaviour of strip footing on geogrid-reinforced sand over a soft clay slope, Geotext and Geomemb, 25(1), pp. 50-60.

[26] Sawwaf, M.E., Nazir, A. (2012). Behaviour of eccentrically loaded small-scale ring footing resting on reinforced layer soil, J GeotechGeoenvironEng, ASCE, 138(3), pp. 376-384. https:// doi.org/10.1061/(ASCE)G.T.1943-5606.0000593

[27] Shin, E.C., Das, B.M. (2000). Experimental study of bearing capacity of a strip foundation on geogrid reinforced sand, GeosynInt J, 7(1), pp. 59-71.
[28] Shin, E.C., Das, B.M., Lee, E.S., Atalar, C. (2002). Bearing capacity of strip foundation on geogrid reinforced sand, GeotechGeolEng, 20, pp. 169-180.

[29] Sireesh, S., Sitharam, T.G., Dash, S.K. (2009). Bearing capacity of circular footing on geocell-sand mattress overlaying clay bed with a void, GeotextGeomemb, 27, pp. 89-98.

[30] Trautmann, C.H., Kulhawy, F.H. (1988). Uplift load-displacement behavior of spread foundations, J GeotechEng, ASCE, 114(2), pp. 168-183.

[31] Yoo, C. (2001). Laboratory investigation of bearing capacity behaviour of strip footing on a geogrid-reinforced sand slope,GeotextGeomemb, 19(5), 279-298. 